Cite this: J. Mater. Chem. C, 2014, 2 , 5247

Received 20th February 2014 Accepted 30th April 2014

DOI: $10.1039 / \mathrm{c} 4 \mathrm{tc} 00345 \mathrm{~d}$

www.rsc.org/MaterialsC

\section{Nanostructured copper oxide semiconductors: a perspective on materials, synthesis methods and applications}

\author{
Ahmad Sabirin Zoolfakar, ${ }^{* a b}$ Rozina Abdul Rani, ${ }^{a}$ Anthony J. Morfa, ${ }^{c}$ \\ Anthony P. O'Mullane ${ }^{\mathrm{d}}$ and Kourosh Kalantar-zadeh ${ }^{\star a}$
}

The oxides of copper $\left(\mathrm{Cu}_{x} \mathrm{O}\right)$ are fascinating materials due to their remarkable optical, electrical, thermal and magnetic properties. Nanostructuring of $\mathrm{Cu}_{x} \mathrm{O}$ can further enhance the performance of this important functional material and provide it with unique properties that do not exist in its bulk form. Three distinctly different phases of $\mathrm{Cu}_{x} \mathrm{O}$, mainly $\mathrm{CuO}, \mathrm{Cu}_{2} \mathrm{O}$ and $\mathrm{Cu}_{4} \mathrm{O}_{3}$, can be prepared by numerous synthesis techniques including, vapour deposition and liquid phase chemical methods. In this article, we present a review of nanostructured $\mathrm{Cu}_{x} \mathrm{O}$ focusing on their material properties, methods of synthesis and an overview of various applications that have been associated with nanostructured $\mathrm{Cu}_{x} \mathrm{O}$.

\section{Introduction}

Lately, there has been a great deal of interest in nanostructured copper oxide $\left(\mathrm{Cu}_{x} \mathrm{O}\right)$ semiconductors. This interest in nanostructured $\mathrm{Cu}_{x} \mathrm{O}$ is fuelled due to their remarkable physical and chemical properties as well as exciting prospects for a variety of applications. ${ }^{\mathbf{1 , 2}}$

${ }^{a}$ School of Electrical and Computer Engineering, RMIT University, Melbourne, VIC 3001, Australia.E-mail: kourosh.kalantar@rmit.edu.au

${ }^{b}$ Faculty of Electrical Engineering, Universiti Teknologi MARA, 40450 Shah Alam, Malaysia. E-mail: ahmado74@salam.uitm.edu.my

${ }^{c}$ Freie Universität Berlin, Fachbereich Physik, 14195 Berlin, Germany

${ }^{d}$ School of Chemistry, Physics and Mechanical Engineering, Queensland University of Technology, GPO Box 2434, Brisbane, QLD, 4001, Australia
Nanostructured copper oxides are relatively abundant in nature, ${ }^{3}$ and a wide range of information is now available for their synthesis. Nanostructured $\mathrm{Cu}_{x} \mathrm{O}$ can be grown using different synthesis techniques, including vapour and liquid phase deposition processes, in which a variety of nanomorphologies can be obtained.

Nanostructured copper oxides are exceptionally versatile and offer unique characteristics in many applications. $\mathrm{Cu}_{x} \mathrm{O}$ nanomaterials have been used as colouring agents for the production of Roman mosaic glasses and antique ceramics for thousands of years. ${ }^{4,5}$ Nanosized $\mathrm{Cu}_{x} \mathrm{O}$ has been widely utilized as a fungicide $^{6,7}$ and in anti-fouling paints ${ }^{8,9}$ due to its biocidal capability. With the advent of nanotechnology, $\mathrm{Cu}_{x} \mathrm{O}$ has shown a great impact in numerous research fields including optics,

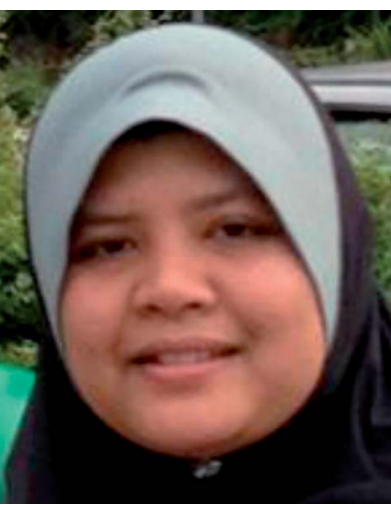

Rozina Abdul Rani received her Bachelor of Engineering (Electrical and Electronic) with Honours (2001) and Master of Science (2007) degree from Universiti Sains Malaysia, Malaysia. She is currently undertaking her candidature for a Ph.D at RMIT University. Her research interests include synthesis and characterization of nanostructured metal oxides, dyesensitized solar cells, chemical sensors and batteries. include aqueous chemical synthesis, gas vapour synthesis, nanotechnology and materials science. At present the prime focus of his work concerns metal oxide for application in sensor development. 
sensors, tribology, superconductors, electrochemistry and electronics. ${ }^{\mathbf{1 0 - 1 4}}$

The most common crystal phases of $\mathrm{Cu}_{x} \mathrm{O}$ are: (a) $\mathrm{CuO}$ also known as copper(II) oxide or cupric oxide where the mineral is known as tenorite, (b) $\mathrm{Cu}_{2} \mathrm{O}$ also known as copper(I) oxide or cuprous oxide with the mineral name of cuprite, and (c) $\mathrm{Cu}_{4} \mathrm{O}_{3}$ with the mineral name of paramelaconite. ,2,15,16 $^{\mathbf{1}}$

In this feature article, we present a general, yet complete, review of nanostructured $\mathrm{Cu}_{x} \mathrm{O}$. The present review is distinguishable from other reviews, ${ }^{\mathbf{1 , 1 7}}$ which have a focus on one type of $\mathrm{Cu}_{x} \mathrm{O}$ (generally $\mathrm{CuO}$ or $\mathrm{Cu}_{2} \mathrm{O}$ ), while this review endeavors to thoroughly discuss three types of $\mathrm{Cu}_{x} \mathrm{O}$, including $\mathrm{CuO}, \mathrm{Cu}_{2} \mathrm{O}$ and $\mathrm{Cu}_{4} \mathrm{O}_{3}$. The organization of this review is as follows: firstly, we discuss the fundamental chemical and physical properties of nanostructured $\mathrm{Cu}_{x} \mathrm{O}$ and then we summarize the different

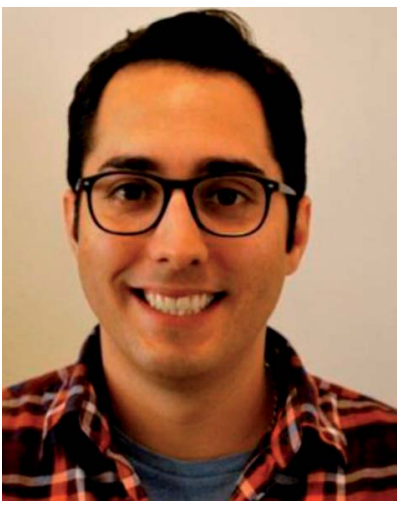

Anthony Morfa earned his Ph.D in physical chemistry from the University of Colorado, Boulder in 2009 under the supervision of Dr Jao van de Lagemaat of the National Renewable Energy Laboratory. He then took a research fellow position at the University of Melbourne, with Prof. Paul Mulvaney before accepting his current Alexander von Humboldt Research Stipendium in the Fachbereich Physik at Freie Universität Berlin with Prof. Dr Michael Giersig. Throughout this time, his research focus has been on studying and enhancing the optical and electronic properties of advanced optoelectronic devices and materials.

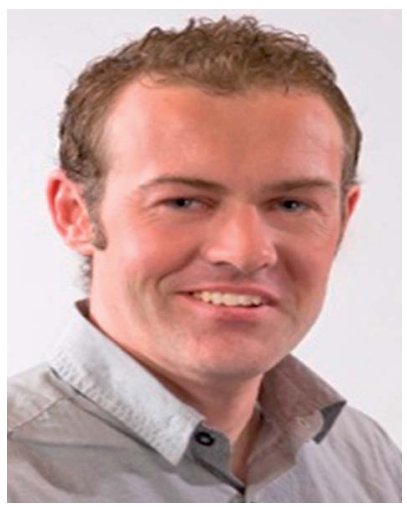

Dr Anthony O'Mullane is an Australian Research Council Future Fellow and Senior Lecturer at the Queensland University of Technology (Australia). He received his Ph.D degree (2001) from University College Cork (Ireland) and completed postdoctoral fellowships at Technische Universitat Darmstadt (Germany), the University of Warwick (UK), and Monash University (Australia).

He previously held a position (2008) at RMIT University (Australia) until moving to QUT in 2013. Dr O'Mullane's research interests are the electrochemical synthesis and characterisation of nanostructured materials; electrocatalysis; catalysis; semi-conducting charge transfer complexes; Li batteries; and the application of electrochemical methods to various aspects of physical, chemical and biological science. methods of synthesis that have been reported. Finally we present a selection of interesting applications that exploit $\mathrm{Cu}_{x} \mathrm{O}$ and illustrate the enhancements made possible by using the nanostructured form of this material.

\section{Fundamental properties}

In this section, the fundamental properties such as crystal structures, electronic band structures, optical and electrical as well as transport properties of nanostructured $\mathrm{Cu}_{x} \mathrm{O}$ are discussed. This section also describes the effect of doping or the presence of impurities on the properties of nanostructured $\mathrm{Cu}_{x} \mathrm{O}$.

\subsection{Crystal structure}

$\mathrm{CuO}$ has a black colour and crystallizes in the monoclinic centered Bravais lattice in the space group of $C 2 / c$. The crystallographic properties of $\mathrm{CuO}$ are tabulated in Table $1 .^{2,15,16,18}$ The copper atom is coordinated to four coplanar oxygen atoms situated at the corners of a rectangular parallelogram, which forms chains by sharing edges. The oxygen atom is coordinated to four copper atoms situated at the corners of a distorted tetrahedron. The chains traverse the structure in the [110] and [110] directions. The two types of chains alternate in the [001] direction and each type is stacked in the [010] direction with a separation between the chains of about $2.7 \AA^{16,18,19}$ Fig. 1a demonstrates the crystal structure of $\mathrm{CuO}$.

$\mathrm{Cu}_{2} \mathrm{O}$ is the second stable phase of copper-oxide compounds which is reddish in colour. $\mathrm{Cu}_{2} \mathrm{O}$ has a cubic structure (space group, $o_{\mathrm{h}}{ }^{4}$ or $P n \overline{3} m$ ) with a lattice constant of $4.2696 \AA$. Each $\mathrm{Cu}$ atom in the unit cell is coordinated by two oxygen atoms. ${ }^{19}$ The crystallographic properties of $\mathrm{CuO}$ are tabulated in Table $1 .^{2,15,16,18}$ Fig. $1 \mathrm{~b}$ demonstrates the crystal structure of $\mathrm{Cu}_{2} \mathrm{O}$.

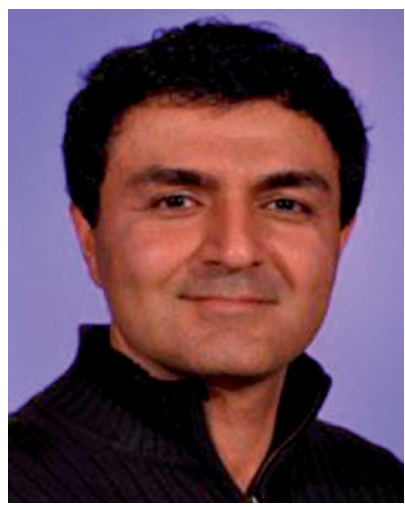

Kourosh Kalantar-zadeh is a Professor at RMIT University, Australia. He received his B.Sc. (1993) and M.Sc. (1997) degrees at the Sharif University of Technology, Iran, and Tehran University, Iran, respectively, and Ph.D at RMIT University, Australia (2002). His research interests include chemical and biochemical sensors, nanotechnology, microsystems, materials science, electronic circuits, and microfluidics. Prof Kalantar-zadeh is the Director of Centre for Advanced Electronics and Sensors (CADES) at RMIT University and the author of approximately 300 peer reviewed scientific papers and books. Prof Kalantar-zadeh is internationally recognized for his research on nanotechnology enabled sensors and two dimensional semiconductors. 
Table 1 Crystallographic properties of $\mathrm{CuO}, \mathrm{Cu}_{2} \mathrm{O}$ and $\mathrm{Cu}_{4} \mathrm{O}_{3}$ (ref. 1-6)

\begin{tabular}{llll}
\hline & $\mathrm{CuO}$ & $\mathrm{Cu}_{2} \mathrm{O}$ & $\mathrm{Cu}_{4} \mathrm{O}_{3}$ \\
\hline Lattice & Monoclinic & Cubic & Tetragonal \\
& $a=4.6837 \AA$ & $a=4.2696 \AA$ & $A=5.837 \AA$ \\
& $b=3.4226 \AA$ & & \\
& $c=5.1288 \AA$ & & \\
& $\beta=99.54^{\circ}$ & & \\
& $\alpha=\gamma=90^{\circ}$ & &
\end{tabular}

\begin{tabular}{|c|c|c|c|}
\hline \multicolumn{4}{|l|}{ Shortest distance } \\
\hline $\begin{array}{l}\text { Interatomic } \\
\text { distances } \mathrm{Cu}-\mathrm{O}\end{array}$ & $1.95 \AA$ & $1.84 \AA$ & $1.87 \AA$ \\
\hline $\begin{array}{l}\text { Interatomic } \\
\text { distances } \mathrm{O}-\mathrm{O}\end{array}$ & $2.62 \AA$ & $3.68 \AA$ & $2.56 \AA$ \\
\hline $\begin{array}{l}\text { Interatomic } \\
\text { distances } \mathrm{Cu}-\mathrm{Cu}\end{array}$ & $2.90 \AA$ & $3.01 \AA$ & $2.92 \AA$ \\
\hline Formula weight & 79.57 & 143.14 & 302.18 \\
\hline Density & $6.52 \mathrm{~g} \mathrm{~cm}^{-3}$ & $5.75 \mathrm{~g} \mathrm{~cm}^{-3}$ & $5.93 \mathrm{~g} \mathrm{~cm}^{-3}$ \\
\hline Melting point & $1201^{\circ} \mathrm{C}$ & $1235^{\circ} \mathrm{C}$ & $400{ }^{\circ} \mathrm{C}$ \\
\hline Cell volume & $81.08 \AA^{3}$ & $77.833 \times 10^{-24} \mathrm{~cm}^{-3}$ & $338 \AA^{3}$ \\
\hline
\end{tabular}

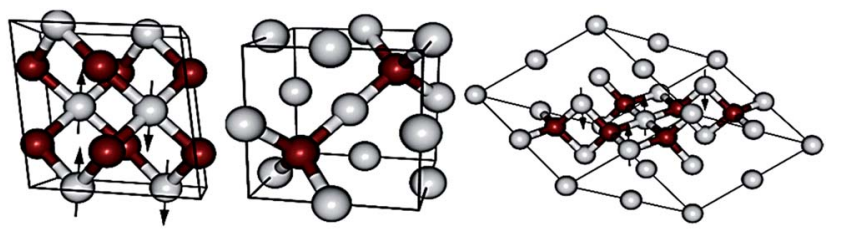

(a)

(b)

(c)

Fig. 1 Monoclinic, cubic and tetragonal crystal structure of the copper oxide compounds (a) $\mathrm{CuO}$, (b) $\mathrm{Cu}_{2} \mathrm{O}$ and (c) $\mathrm{Cu}_{4} \mathrm{O}_{3}$ (gray and red spheres represent copper and oxygen atoms, respectively). For the antiferromagnetic $\mathrm{CuO}$ and $\mathrm{Cu}_{4} \mathrm{O}_{3}$ the arrows on the copper ions indicate the orientation of local magnetic moments. Reprinted figure with permission from (M. Heinemann, B. Eifert and C. Heiliger, Phys. Rev. B, 2013, 87) copyright (2013) by the American Physical Society.

The third stable phase of copper-oxide with an atomic ratio of 1.33 is $\mathrm{Cu}_{4} \mathrm{O}_{3} \cdot{ }^{20} \mathrm{Cu}_{4} \mathrm{O}_{3}$ is a mixture of $\mathrm{Cu}(\mathrm{I}) / \mathrm{Cu}$ (II) oxide. The local coordination environments of $\mathrm{Cu}(\mathrm{I})$ and $\mathrm{Cu}(\mathrm{II})$ are similar to the ones found in $\mathrm{Cu}_{2} \mathrm{O}$ and $\mathrm{CuO}^{21}$ This less studied compound of the $\mathrm{Cu}_{x} \mathrm{O}$ family was first discovered in 1870 as a mineral in the Copper Queen mine (Arizona, US). ${ }^{2} \mathrm{Cu}_{4} \mathrm{O}_{3}$ belongs to the tetragonal structure (space group, I4 $/$ /amd) with a lattice constant of $a=5.837 \AA$ and $c=9.932 \AA{ }^{21}$ Fig. 1c demonstrates the crystal structure of $\mathrm{Cu}_{4} \mathrm{O}_{3}$. From the crystal structure, one can observe that there are two types of copper ions which are $\mathrm{Cu}^{+}$ and $\mathrm{Cu}^{2+}$. The $\mathrm{Cu}^{+}$ion has two oxygen atoms as nearest neighbours forming collinear bonds of length $1.87 \AA$ which is similar to cuprite $\left(\mathrm{Cu}_{2} \mathrm{O} \sim 1.85 \AA\right)$. Similarly, the $\mathrm{Cu}^{2+}$ ion is surrounded by four oxygen atoms with bond lengths and angles being very close to those observed in tenorite $(\mathrm{CuO}) .{ }^{\mathbf{1 8 , 1 9 , 2 1}}$ The crystallographic properties of $\mathrm{Cu}_{4} \mathrm{O}_{3}$ are tabulated in Table 1., 21,22

\subsection{Electronic band structure}

The reported band gap $\left(E_{\mathrm{g}}\right)$ values for $\mathrm{CuO}$, which is a p-type semiconductor, are generally in the range of 1.2 to $2.16 \mathrm{eV} .^{1,23-27}$
This wide range is attributed to several factors, including interpretation of the nature of the gap (i.e. direct or indirect), annealing treatment, grain dimensions, morphology and doping. ${ }^{1,25,28-30}$ According to the Tauc relationship, for photon energies $(E)$ greater than the band gap energy, the light absorption can be approximated using: ${ }^{31}$

$$
\alpha E=\alpha_{\mathrm{o}}\left(E-E_{\mathrm{g}}\right)^{\eta}
$$

where $\alpha$ is the absorption coefficient, $\alpha_{\mathrm{o}}$ is a constant, $E_{\mathrm{g}}$ is the band gap energy and $\eta$ is an exponent that depends on the type of transition involved. The value of $\eta$ is $\frac{1}{2}$ or 2 for direct or indirect transitions, respectively. Rakhshani et al. have reported detailed studies of band gap determination of RF sputtered $\mathrm{CuO}$ films. ${ }^{23}$ They found that their $\mathrm{CuO}$ films exhibited an indirect transition with a band gap of $1.21 \mathrm{eV}$. In contrast, Pierson et al., while reporting the same deposition technique (RF sputtering), determined that their $\mathrm{CuO}$ films exhibited a direct band gap with a value of $1.71 \mathrm{eV} .^{32}$ The different values of $E_{\mathrm{g}}$ were due to different models $\left((\alpha E)^{2}\right.$ or $\left.(\alpha E)^{\frac{1}{2}}\right)$ being used to determine the band gap value. The other significant factor that contributes to the variation of band gap values of $\mathrm{CuO}$ films is related to the heat treatment. ${ }^{29,30}$ Izaki et al. demonstrated that annealing electrodeposited $\mathrm{CuO}$ films altered the $E_{\mathrm{g}}$ value. ${ }^{29}$ They reported a reduction of $7.5 \%$ in $E_{\mathrm{g}}$ after annealing the as-deposited $\mathrm{CuO}$ at $773 \mathrm{~K}$. They suggested that the changes in the composition, grain size and lattice constant were induced by the annealing process, altering the $\mathrm{CuO}$ band gap. ${ }^{29}$

In nanostructured $\mathrm{CuO}$, the band gap generally increases with reducing crystallite dimensions. ${ }^{1,33}$ Experimentally, this is often observed as a blue shift of the optical absorption bandedge when the nanostructure dimensions are reduced. The blue shift can be attributed to the quantum confinement (QC) effect. $^{1,34,35}$ The strong QC effect occurs when the size of the crystal is reduced much smaller than the Bohr radius for the material $(\approx 6.6 \mathrm{~nm}$ for $\mathrm{CuO}) .{ }^{1}$ This causes direct changes to the electron wavefunctions and hence significantly alters the $E_{\mathrm{g}}$. A weak QC effect occurs when the crystal size is larger than the Bohr radius. This causes indirect perturbation of the electron wavefunction due to Coulomb effects and results in more subtle changes in the band gap energy. ${ }^{34,35}$ In a recent study conducted by Rehman et al., different scales of $\mathrm{CuO}$ nanoparticles were reported, where the crystallite dimension is controlled by annealing. ${ }^{33}$ The crystallite dimensions obtained ranged from $11 \mathrm{~nm}\left(T=250{ }^{\circ} \mathrm{C}\right)$ to $20 \mathrm{~nm}\left(T=600{ }^{\circ} \mathrm{C}\right)$. They reported a reduction of $7 \%$ in direct $E_{\mathrm{g}}$ with an increase of crystallite dimensions. ${ }^{33}$ In addition, it has been reported that the band gap values of nanostructured $\mathrm{CuO}$ can be tuned via engineering the morphology ${ }^{36-38}$ as well as doping. ${ }^{39-42}$

$\mathrm{Cu}_{2} \mathrm{O}$ is also a p-type semiconductor material due to the presence of copper vacancies. ${ }^{2,43}$ It is a direct band gap material with $E_{\mathrm{g}}>2.1 \mathrm{eV}$. However the band gap can be tuned via engineering the grain dimensions..$^{\mathbf{2 4 , 2 8 , 3 0 , 4 4 , 4 5}}$ This observation is widely attributed to the QC effect in smaller grains, causing a blue shift in the band gap..$^{34,35,46}$ In a recent study conducted by Poulopoulos et al., ${ }^{46}$ on $\mathrm{Cu}_{2} \mathrm{O}$ thin films with thicknesses 

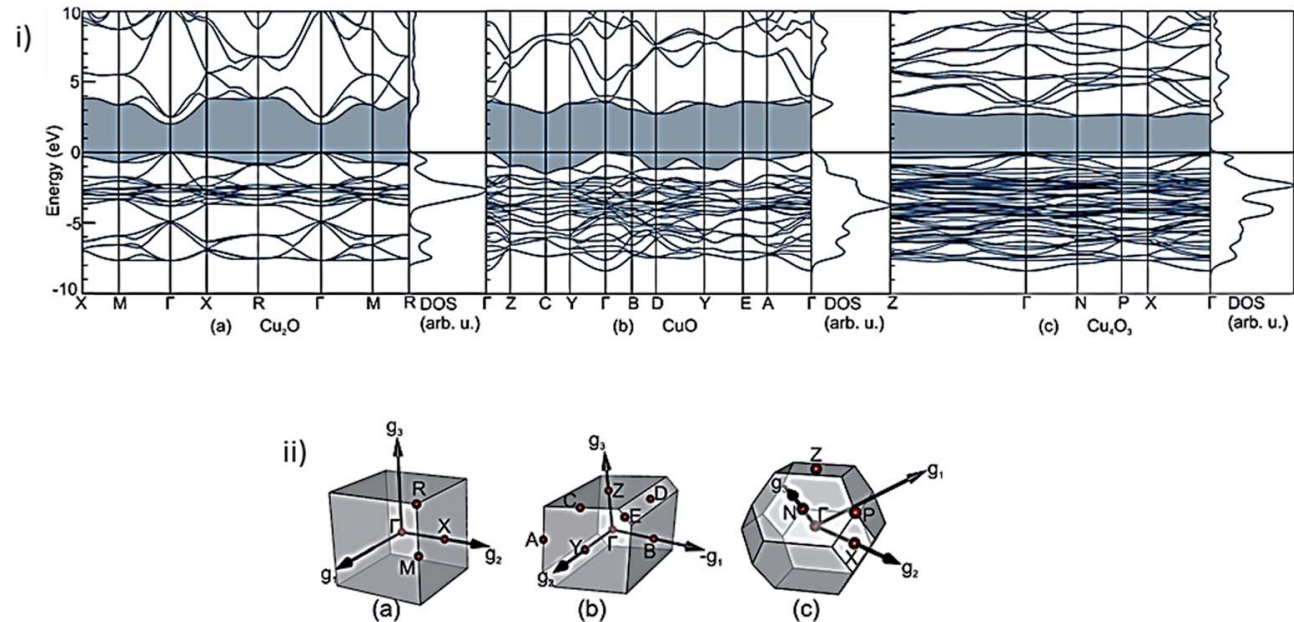

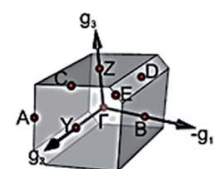

(b)

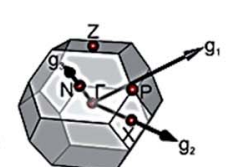

(c)

Fig. 2 (i) Electronic band structure and density of states from hybrid functional DFT calculations and (ii) Brillouin zones with special high symmetry $k$ points of the three copper oxide compounds to: (a) $\mathrm{Cu}_{2} \mathrm{O}$, (b) $\mathrm{CuO}$ and (c) $\mathrm{Cu}_{4} \mathrm{O}_{3}$. Reprinted figure with permission from (M. Heinemann, B. Eifert and C. Heiliger, Phys. Rev. B, 2013, 87) copyright (2013) by the American Physical Society.

ranging from 0.75 to $5.4 \mathrm{~nm}$ the $E_{\mathrm{g}}$ value increased significantly from $\sim 2.6 \mathrm{eV}(5.4 \mathrm{~nm}$ film thickness) to $\sim 3.8 \mathrm{eV}(0.75 \mathrm{~nm}$ film thickness) due to QC effects. In addition, Balamurugan et al. ${ }^{45}$ and Chang $\mathrm{Y}$ et $a .^{44}$ also reported on the observation of QC effects in $\mathrm{Cu}_{2} \mathrm{O}$. They further studied the effect of temperature ${ }^{45}$ and annealing duration ${ }^{44}$ on manipulating the crystallite sizes and hence altering the band gap of $\mathrm{Cu}_{2} \mathrm{O}$.

Similar to $\mathrm{CuO}$, the optical band gap of $\mathrm{Cu}_{4} \mathrm{O}_{3}$ has also been reported with a wide range of values from 1.34 to $2.47 \mathrm{eV}$ which can also be attributed to the interpretation of the type of band gap and whether direct or indirect transitions are allowed. ${ }^{\mathbf{2 0 , 3 2 , 4 7 , 4 8}}$

A good comparison between the electronic properties of the three types of $\mathrm{Cu}_{x} \mathrm{O}$ is presented via the band structure density functional theory (DFT) calculations by Heinemann et al. (Fig. 2i). ${ }^{19}$ Fig. 2ii illustrates the Brillouin zones with special high symmetry $k$ points of the three copper oxide compounds, which were used for the band structure DFT calculations. ${ }^{19}$

\subsection{Optical properties}

The optical behaviour of $\mathrm{Cu}_{x} \mathrm{O}$ films have been experimentally studied, in particular the complex dielectric function $(\varepsilon(E)=$ $\left.\varepsilon_{1}(E)+i \varepsilon_{2}(E)\right)$ was determined via spectroscopic ellipsometry. ${ }^{2,49,50}$ For comparison, the imaginary part $\left(\varepsilon_{2}\right)$ of the dielectric function for $\mathrm{CuO}, \mathrm{Cu}_{2} \mathrm{O}$ and $\mathrm{Cu}_{4} \mathrm{O}_{3}$ is shown in Fig. 3(a) and (b) with Gaussian fitting marked with numbers 1 to 7 . For $\mathrm{Cu}_{2} \mathrm{O}$ the peaks originate from the various band gaps corresponding to $2.59 \mathrm{eV}(1), 2.71 \mathrm{eV}(2), \ldots 5.24 \mathrm{eV}(7) .^{2}$ The difference in energy between these two first peaks is attributed to the spin-orbit splitting energy of $\sim 0.12 \mathrm{eV}$ for $\mathrm{Cu}_{2} \mathrm{O} .{ }^{49}$ The absence of any sharp peaks for the $\mathrm{CuO}\left(\varepsilon_{2}\right)$ spectrum is due to low symmetry of this crystal. Similarly no sharp peak is seen for $\mathrm{Cu}_{4} \mathrm{O}_{3}$ for energies of less than $3.7 \mathrm{eV}$.

There are many reports regarding the absorption coefficient $\alpha(E)$ and normal-incidence reflectivity $R(E)$ of $\mathrm{Cu}_{x} \mathrm{O}$ films in optical ranges. ${ }^{2,49-51} \mathrm{Cu}_{2} \mathrm{O}$ is expected to have an essentially full $\mathrm{Cu} 3 \mathrm{~d}$ shell with a direct forbidden band gap of $2.17 \mathrm{eV}$ in the bulk, which can only absorb light up to the visible region. In contrast, CuO has an open 3d shell with a direct band gap (1.2 eV in bulk) of charge-transfer type, which can absorb light up to the near infrared (IR) region. ${ }^{\mathbf{1 1 5 , 2 7}}$ A detailed analysis of the absorption coefficient obtained on bulk and thin film $\mathrm{Cu}_{2} \mathrm{O}$ can be found in the report by Malerba et al. ${ }^{51}$ Additionally, Rehman et al. and Borgohain et al. reported the optical absorption properties of $\mathrm{CuO}$ and $\mathrm{Cu}_{2} \mathrm{O}$ nanoparticles of different sizes, respectively. ${ }^{33,52} \mathrm{~A}$ comparative study of optical absorption between nanoparticles and near-monodisperse nanospheres of $\mathrm{Cu}_{2} \mathrm{O}$ has been reported by Zhang et al. ${ }^{53}$ They found that the nanospheres of $\mathrm{Cu}_{2} \mathrm{O}$ have a wide absorption peak at $520 \mathrm{~nm}$ while $\mathrm{Cu}_{2} \mathrm{O}$ nanoparticles have an absorption edge at $550 \mathrm{~nm} .^{53}$

Mayer et al. have reported that $\mathrm{CuO}$ is nonluminescent. ${ }^{2}$ This is despite a few reports demonstrating the photoluminescence (PL) of CuO films, however the purity of such films is questionable (the presence of $\mathrm{Cu}_{2} \mathrm{O}$ is a possibility). Nevertheless, Zhang et al. reported a detailed analysis of the PL properties of CuO nanostructures. They found that the PL properties of nanostructured $\mathrm{CuO}$ can be controlled via altering their shape, dimension and morphology. ${ }^{1}$ The QC effect and the specific surface effect are the two most reported mechanisms which can
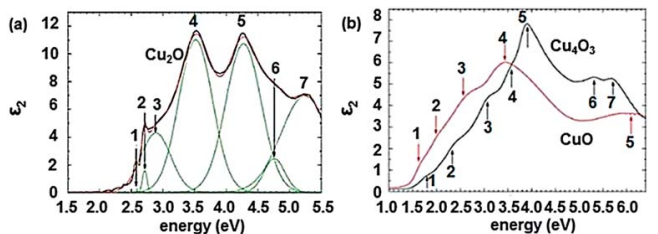

Fig. 3 Gaussian fit to the imaginary part of the dielectric $\varepsilon_{2}$ for (a) $\mathrm{Cu}_{2} \mathrm{O}$, (b) $\mathrm{CuO}$ and $\mathrm{Cu}_{4} \mathrm{O}_{3}$. Reprinted with permission from (B. K. Meyer, A. Polity, D. Reppin, M. Becker, P. Hering, P. J. Klar, T. Sander, C. Reindl, J. Benz, M. Eickhoff, C. Heiliger, M. Heinemann, J. Blaesing, A. Krost, S. Shokovets, C. Mueller and C. Ronning, Phys. Status Solidi B, 2012, 249, 1487-1509) copyright (2012) by WILEY-VCH Verlag GmbH \& Co. KGaA, Weinheim. 


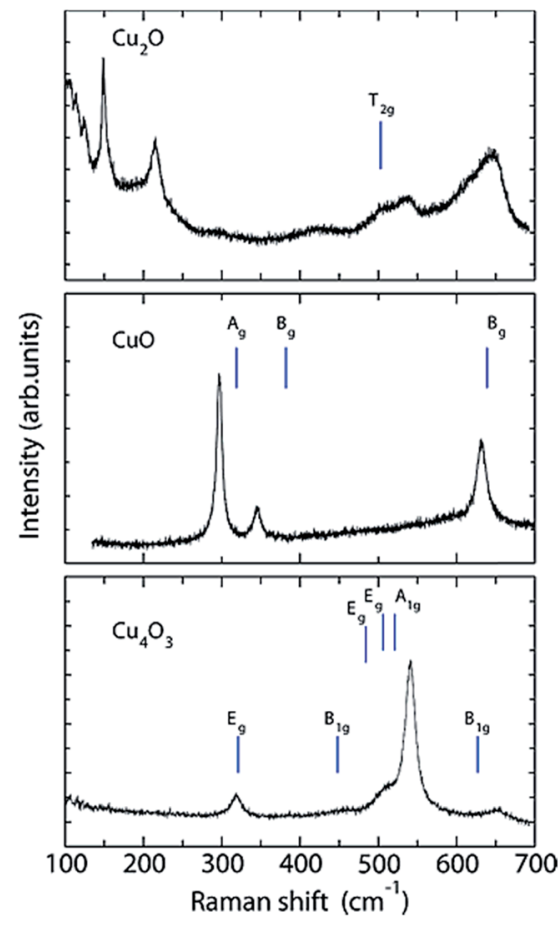

Fig. 4 Experimental Raman spectra of $\mathrm{Cu}_{2} \mathrm{O}, \mathrm{CuO}$ and $\mathrm{Cu}_{4} \mathrm{O}_{3}$. The calculated frequencies of Raman active vibrational modes are indicated by vertical bars. Reprinted with permission from (L. Debbichi, M. C. M. de Lucas, J. F. Pierson and P. Kruger, J. Phys. Chem. C, 2012, 116, 10232-10237) copyright (2012) American Chemical Society.

result in the blue shift and red shift of the PL peak, respectively. ${ }^{1,54}$ On the other hand, $\mathrm{Cu}_{2} \mathrm{O}$ shows a weak PL effect due to the fact that optical transitions require parity change, which does not exist between the energetically highest valence band and lowest conduction band of the $\mathrm{Cu}_{2} \mathrm{O}$ direct transition band. ${ }^{2}$ In bulk $\mathrm{Cu}_{2} \mathrm{O}$, there are three peaks or shoulders that can be assigned to doubly charged oxygen vacancies $\left(V_{\mathrm{o}}{ }^{2+}\right)$ at $1.72 \mathrm{eV}$ $(720 \mathrm{~nm})$, singly charged oxygen vacancies $\left(V_{\mathrm{cu}}{ }^{1+}\right)$ at $1.53 \mathrm{eV}$ $(810 \mathrm{~nm})$ and copper vacancies $\left(V_{\mathrm{cu}}\right)$ at $1.35 \mathrm{eV}(920 \mathrm{~nm}) .^{2}$ In nanostructured $\mathrm{Cu}_{2} \mathrm{O}$, these peaks and shoulders can be tuned via shape, dimension and morphology alterations as observed by Shi et al. ${ }^{55,56}$

\subsection{Vibrational properties}

The lattice dynamics of $\mathrm{Cu}_{x} \mathrm{O}$ materials have been studied using IR, Raman and photoluminescence spectroscopy. ${ }^{57-61}$ These studies provided insight into the nature of the electron phonon interaction and the negative thermal expansion (NTE) in $\mathrm{Cu}_{x} \mathrm{O}$. These methods also provided information about spin-phonon interaction and size dependent electron phonon scattering. ${ }^{61}$ Debbichi $e t$ al. reported an extensive study of vibrational properties of $\mathrm{Cu}_{x} \mathrm{O}$ via Raman spectroscopy where they clearly distinguished the different types of vibrational modes either by Raman or IR spectroscopy. ${ }^{61}$ Recently, Shih et al. have reported studies on the size effects of spin-phonon coupling in in-plane $\mathrm{CuO}$ nanowires. ${ }^{62}$ They employed low-temperature Raman spectroscopy for probing the local atomic vibrations of nanowires. They found that the spin-phonon mode varies with the size of the $\mathrm{CuO}$ nanowires due to the increase in the strength of the spin-phonon coupling. ${ }^{62}$

The IR spectroscopy modes are associated with the relative motion of both copper and oxygen atoms which consist of asymmetric $\mathrm{Cu}-\mathrm{O}$ stretching and asymmetric $\mathrm{O}-\mathrm{Cu}-\mathrm{O}$ bending modes. In contrast, Raman active modes only involve the relative motion of oxygen atoms. ${ }^{63}$ Fig. 4 shows Raman spectra of $\mathrm{Cu}_{x} \mathrm{O}$ with calculated frequencies of Raman active vibrational modes. ${ }^{61}$ The symmetries of the zone-center modes are given by the following representations: ${ }^{2,61}$

$$
\begin{gathered}
\Gamma_{\mathrm{Cu}_{2} \mathrm{O}}=\mathrm{A}_{2 \mathrm{u}}+\mathrm{E}_{\mathrm{u}}+3 \mathrm{~T}_{1 \mathrm{u}}+\mathrm{T}_{2 \mathrm{u}}+\mathrm{T}_{2 \mathrm{~g}} \\
\Gamma_{\mathrm{CuO}}=\mathrm{A}_{\mathrm{g}}+2 \mathrm{~B}_{\mathrm{g}}+4 \mathrm{~A}_{\mathrm{u}}+5 \mathrm{~B}_{\mathrm{u}} \\
\Gamma_{\mathrm{Cu}_{4} \mathrm{O}_{3}}=3 \mathrm{E}_{\mathrm{g}}+\mathrm{A}_{1 \mathrm{~g}}+2 \mathrm{~B}_{1 \mathrm{~g}}+9 \mathrm{E}_{\mathrm{u}}+6 \mathrm{~A}_{2 \mathrm{u}}+5 \mathrm{~B}_{2 \mathrm{u}}+2 \mathrm{~B}_{1 \mathrm{u}}+2 \mathrm{~A}_{1 \mathrm{u}}
\end{gathered}
$$

\subsection{Electrical properties}

The electrical conductivity and hole density of p-type $\mathrm{Cu}_{2} \mathrm{O}$ films vary with copper vacancy density, which act as shallow acceptors. ${ }^{2}$ Similarly in $\mathrm{CuO}$, copper deficiencies account for the intrinsic p-type semiconducting behaviour. ${ }^{64}$ Suda et al. and Young et al. have studied the effect of temperature on electrical conductivity of $\mathrm{CuO}$ and $\mathrm{Cu}_{2} \mathrm{O}$ films, respectively (Fig. 5(a) and (b)). ${ }^{65,66}$ They have shown that an increase in temperature increases the conductivity of $\mathrm{CuO}$ and $\mathrm{Cu}_{2} \mathrm{O}$ due to an increase in the hole concentration. ${ }^{65}$ Similar findings were also reported by Gopalakrishna et al. ${ }^{67}$ using Hall effect studies. They revealed a significant increase in conductivity, mobility and carrier concentration of nanocrystalline $\mathrm{CuO}$ after annealing. ${ }^{67}$ Apart from temperature, electrical properties of $\mathrm{Cu}_{x} \mathrm{O}$ also relied on grain dimensions, grain boundary, film thickness, specific phase and dopants. ${ }^{1-3,68-72}$ Shao et al. reported an electrical conductivity of individual single $\mathrm{CuO}$ nanowires grown by thermal oxidation. ${ }^{69}$ The electrical transport measurement has shown that the $\mathrm{CuO}$ nanowire has a conductivity of $7.8 \times 10^{-4}$ $(\Omega \mathrm{cm})^{-1}{ }^{69}$ Additionally, Liao et al. reported that individual $\mathrm{Cu}_{2} \mathrm{O}$ nanowires have a high mobility of $>95 \mathrm{~cm}^{2} \mathrm{~V}^{-1} \mathrm{~s}^{-1} .{ }^{70}$ It is possible to tune the electrical properties (resistivity, carrier concentration and mobility) of $\mathrm{Cu}_{x} \mathrm{O}$ by changing the stoichiometry and crystallinity of the $\mathrm{Cu}_{x} \mathrm{O}$ films during the deposition process. Deposition parameters, such as $\mathrm{pH}$ of the solution in electrodeposition and hydrothermal methods and ion pressure and concentration in RF sputtering techniques, significantly contribute to changes in stoichiometry and crystallinity. ${ }^{73-75}$

\subsection{Thermal properties}

A limited number of studies have been carried out on the thermal properties of pristine copper oxide films. However, great interest has been shown for the development of nanoparticles of $\mathrm{Cu}_{x} \mathrm{O}$ suspensions in fluids (nanofluids) due to the significant enhancement of thermal conductivity that they grant to the fluid in which they are suspended. ${ }^{76-79}$ The relatively high thermal conductivity of $\left.\mathrm{CuO}(76.5 \mathrm{~W} \mathrm{mK})^{-1}\right)^{78}$ makes it an excellent candidate for enhancing the efficiency and reliability 
(a)

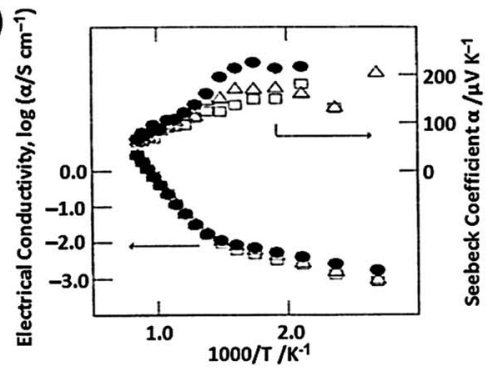

(c)

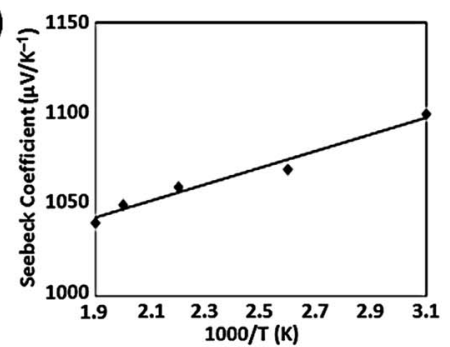

(b)

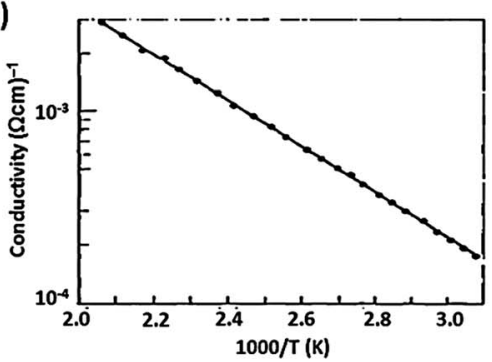

(d)

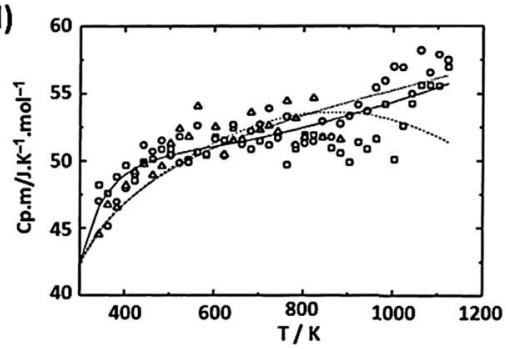

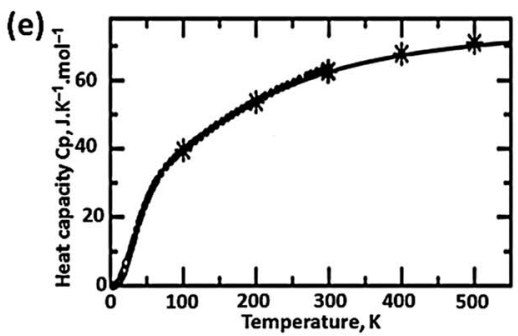

Fig. 5 (a) Temperature dependence for electrical conductivity and the Seebeck coefficient of CuO in oxygen $(\bullet)$, in air $(\Delta)$ and in $3 \% \mathrm{O}_{2}-\operatorname{Ar}(\square)$, (b) electrical conductivity of $\mathrm{Cu}_{2} \mathrm{O}$ single crystal vs. $1 / T$, (c) Seebeck coefficient of $\mathrm{Cu}_{2} \mathrm{O}$ single crystal vs. $1 / T$, calculated and experimental heat capacities, $C_{p}$ of (d) $\mathrm{CuO}:(\square \Delta \mathrm{O})$ ref. 89, ( $\left.\cdots\right)$ ref. 90, (- - ) ref. 91, and (e) $\mathrm{Cu}_{2} \mathrm{O}:(-)$ ref. 88, (O) ref. $92(0)$ ref. 93 . Reprinted with permission from (a) (S. Suda, S. Fujitsu, K. Koumoto and H. Yanagida, Jpn. J. Appl. Phys. 1, 1992, 31, 2488-2491) copyright (1992) by The Japan Society of Applied Physics, (b and c) reprinted from A. P. Young and C. M. Schwartz, J. Phys. Chem. Solids, 30, 249-252, copyright (1969) with permission from Elsevier, (d) reprinted from Thermochim. Acta, 348, J. Leitner, D. Sedmidubský, B. Doušová, A. Strejc and M. Nevřiva 49-51, copyright (2000) with permission from Elsevier, (e) (P. A. Korzhavyi, I. L. Soroka, E. I. Isaev, C. Lilja and B. Johansson, P. Natl. Acad. Sci. USA, 2012, 109, 686-689) copyright (2012) National Academy of Science, USA.

of refrigeration and air conditioning systems. ${ }^{\mathbf{8 0 , 8 1}}$ In contrast, $\mathrm{Cu}_{2} \mathrm{O}$ has a rather low thermal conductivity of the order of $4.5 \mathrm{~W}$ $\mathrm{mK}^{-1} .^{\mathbf{8 2 , 8 3}}$ It has been shown that the thermal conductivity enhancement of both $\mathrm{CuO}$ and $\mathrm{Cu}_{2} \mathrm{O}$ nanofluids corresponds to an increased particle volume fraction and temperature. ${ }^{\mathbf{8 4 - 8 7}}$

The variations in the Seebeck coefficient $(S)$ of $\mathrm{CuO}$ and $\mathrm{Cu}_{2} \mathrm{O}$ as a function of temperature are shown in Fig. 5(a) and (c) for which both oxides show decreasing trends. It has been shown that at $500 \mathrm{~K}, \mathrm{CuO}$ and $\mathrm{Cu}_{2} \mathrm{O}$ exhibit a maximum value of $200 \mu \mathrm{V} \mathrm{K}^{-1}$ and $1050 \mu \mathrm{V} \mathrm{K}^{-1}$, respectively. ${ }^{65,66}$

The presence of a wide gap in the phonon spectra between low frequency (due to acoustic and optical phonon modes that involve the motion of $\mathrm{Cu}$ atoms) and high frequency (due to the optical modes of oxygen vibrations) bands are reflected in the temperature dependence of heat capacity. ${ }^{88}$ The calculated and experimental heat capacities $\left(C_{\mathrm{p}}\right)$ of $\mathrm{CuO}$ and $\mathrm{Cu}_{2} \mathrm{O}$ as a function of temperature are shown in Fig. (5d) and (e). ${ }^{88-93}$ As seen from the figure, the shape of $C_{\mathrm{p}} v s$. temperature curves for both $\mathrm{CuO}$ (for temperatures below $800 \mathrm{~K}$ ) and $\mathrm{Cu}_{2} \mathrm{O}$ (for temperatures below $500 \mathrm{~K}$ ) are accurately accounted for by the calculations that employ the quasi-harmonic approximation. ${ }^{88}$

\subsection{Magnetic properties and superconductivity}

The copper-oxygen covalent bond is the prominent factor governing the properties of high transition temperature (High- $T_{\mathrm{c}}$ ) superconducting $\mathrm{Cu}_{x} \mathrm{O}$ compounds. ${ }^{94}$ Both $\mathrm{CuO}$ and $\mathrm{Cu}_{4} \mathrm{O}_{3}$ have an antiferromagnetic ground state. For $\mathrm{CuO}$ the antiferromagnetic unit cell has twice the size of the primitive unit cell of the crystal. ${ }^{19}$ In the case of $\mathrm{Cu}_{4} \mathrm{O}_{3}$, it was suggested that the antiferromagnetic unit cell doubles the crystallographic unit cell in all three special directions. ${ }^{19,95-97}$ Bulk $\mathrm{CuO}$ is antiferromagnetic with Néel temperatures from $213 \mathrm{~K}$ to $230 \mathrm{~K} .^{\mathbf{1 , 9 8 , 9 9}}$ The $\mathrm{CuO}$ antiferromagnetic transition takes place in two stages: near $230 \mathrm{~K}$ it leads to incommensurate antiferromagnetic order and near $213 \mathrm{~K}$ by a first order transition to a commensurate antiferromagnetic order. ${ }^{94}$ As mentioned in Section 2.1, the copper atom of $\mathrm{CuO}$ is surrounded by four coplanar oxygen atoms, resulting in two sets of one dimensional $\mathrm{Cu}-\mathrm{O}$ chains. The magnetic interaction due to super exchange leads to antiferro-

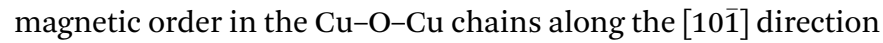
with a bond angle of $146^{\circ} .{ }^{94}$ Magnetic properties of nanostructured $\mathrm{CuO}$ significantly rely on their grain dimensions, morphology as well as anisotropy of the nanostructures. ${ }^{1}$ 
A diameter of $10 \mathrm{~nm}$ is the critical size for $\mathrm{CuO}$ nanoparticles to show ferromagnetic behaviour., ${ }^{\mathbf{1 0 0 - 1 0 2}}$ Interestingly, there are reports regarding room-temperature ferromagnetism of pure $\mathrm{CuO}$ nanostructures. ${ }^{\mathbf{1 , 1 0 3 - 1 0 5}}$ The room-temperature ferromagnetism is due to oxygen vacancies at the surface/or interface of the nanoparticles. ${ }^{\mathbf{1 , 1 0 5}}$

A neutron diffraction study revealed that $\mathrm{Cu}_{4} \mathrm{O}_{3}$ undergoes a magnetic phase transition below $42.3 \mathrm{~K}$ leading to a pyrochlore lattice. ${ }^{95,96}$ The amplitude of the magnetic moment carried by $\mathrm{Cu}^{2+}$ is $\sim 0.46 \mu_{\beta}$ which indicates the strong covalent character of the $\mathrm{Cu}-\mathrm{O}$ bonds and the presence of strong fluctuations even at low temperatures. ${ }^{95}$

Compounds made of $\mathrm{Cu}$ and $\mathrm{O}$ are the base of a famous class of high- $T_{\mathrm{c}}$ superconductors. ${ }^{94}$ Superconductivity in these materials is observed when they are strongly doped away from their ideal stoichiometry. It has been shown that spatial changes in carrier density and the superconducting gap produce local inhomogeneity, which strongly affects their superconductivity. ${ }^{\mathbf{1 0 6}}$

High- $T_{\mathrm{c}}$ was first discovered by Bednorz and Müller in 1986 using $\mathrm{Cu}$ and $\mathrm{O}$ compounds such as $\mathrm{La}_{2} \mathrm{CuO}_{4}$ doped with $\mathrm{Ba} \cdot{ }^{107} \mathrm{~A}$ few months later it was found that doping the same material with $\mathrm{Sr}$ raised the superconducting critical temperature to nearly $40 \mathrm{~K} \cdot{ }^{107}$ Recently, the performance of high- $T_{\mathrm{c}}$ copper and oxygen based materials was further enhanced with the inclusion of extra oxygen atoms as mobile "holes" into the copper oxide planes as illustrated in the $\mathrm{Bi}_{2} \mathrm{Sr}_{2} \mathrm{CaCu}_{2} \mathrm{O}_{8+x}$ and $\mathrm{YBa}_{2} \mathrm{Cu}_{3} \mathrm{O}_{6+x}$ systems. ${ }^{106,108}$ Apart from providing charge carriers, the role of oxygen dopants is still debatable and being investigated. ${ }^{\mathbf{1 0 6 , 1 0 8 - 1 1 0}}$

\subsection{Doping}

It is possible to modify the chemical and physical properties of $\mathrm{Cu}_{x} \mathrm{O}$ through doping. It has been shown that doping has the capability to alter the conduction type of $\mathrm{Cu}_{2} \mathrm{O}$ (from $\mathrm{p}$ to $\mathrm{n}$ ). Based on the valencies of $\mathrm{Cu}$ and $\mathrm{O}$, which are +1 and -2 in $\mathrm{Cu}_{2} \mathrm{O}$, some n-type dopants including group VII elements such as halogens (O sites) (and possibly group II elements ( $\mathrm{Cu}$ sites)) allow this transition to occur. ${ }^{111}$ The typical reported halogen dopants include fluorine $(\mathrm{F})$, chlorine $(\mathrm{Cl})$ and bromine $(\mathrm{Br})$ which can be intercalated into the structure of $\mathrm{Cu}_{2} \mathrm{O}$ during the synthesis process. ${ }^{\mathbf{1 1 1 - 1 1 4}}$ Theoretically, $\mathrm{F}$ is the best match for $\mathrm{O}$ given the similarity in the size; however, CuF is soluble in water. $^{111}$ Recently, Scanlon et al. have demonstrated that intrinsic n-type defects or defect complexes in $\mathrm{Cu}_{2} \mathrm{O}$ created during an electrodeposition process cannot be the source of any n-type behaviour. ${ }^{75}$ They have suggested that the n-type conduction is due to an inversion layer which was attributed to a shallow donor level being formed during the electrodeposition process or due to external impurities (dopants). ${ }^{75}$

Generally, the hole density of native p-type $\mathrm{Cu}_{x} \mathrm{O}$ films is poor, uncontrollable and sensitive to the preparation methods and experimental conditions. It has been reported that nitrogen $(\mathrm{N})$ and silicon $(\mathrm{Si})$ doped $\mathrm{Cu}_{2} \mathrm{O}$ via a $\mathrm{RF}$ sputtering process can significantly reduce such instabilities. ${ }^{\mathbf{1 1 5 - 1 1 8}}$ These dopants were found to act as acceptors, which are incorporated into the oxygen lattice without converting the conduction type of $\mathrm{Cu}_{2} \mathrm{O} .{ }^{117,118}$ To further stabilize the films Ishizuka et al. and Okamoto et al. investigated the effect of passivation using hydrogen $(\mathrm{H})$ and crown-ether cyanide of the $\mathrm{N}$ doped $\mathrm{Cu}_{2} \mathrm{O}$ films. ${ }^{115,119}$ The improvement after the treatment indicates that hole traps are passivated by cyanide or protons. These hole traps are generally due to oxygen vacancies or dangling bonds of $\mathrm{Cu} .{ }^{\mathbf{1 1 5}}$

For solar cell applications, the intrinsic photoconductivity of $\mathrm{Cu}_{2} \mathrm{O}$ can be limited by minority charge carrier recombination caused by native defects acting as trap states. Isseroff $e t$ al. used first principles DFT calculations to study these trap states and demonstrated that substitutional cation doping reduces the recombination effect. ${ }^{43}$ They found that split vacancies are the source of trap states that inhibit the minority carrier diffusion in $\mathrm{Cu}_{2} \mathrm{O}$. Dopants such as lithium (Li), magnesium $(\mathrm{Mg})$, manganese (Mn), and zinc ( $\mathrm{Zn}$ ) prevent the formation of the split vacancies for a single cation vacancy which resulted in an electronic structure that exhibited no trap states within the band gap. ${ }^{43}$

\section{Nanostructured $\mathrm{Cu}_{x} \mathrm{O}$ synthesis}

Many different approaches for the synthesis of nanostructured $\mathrm{Cu}_{x} \mathrm{O}$ have been implemented using both vapour and liquidphase-based methods. In this section, we present the most common synthesis methods and describe how they can be employed for engineering and tuning the morphologies and properties of $\mathrm{Cu}_{x} \mathrm{O}$.

\subsection{Vapour phase synthesis}

Vapour phase synthesis methods can be divided into two different categories: (i) physical vapour deposition (PVD) and (ii) chemical vapour deposition (CVD). The main difference between them is the process they employ, in which PVD uses physical forces to deposit films, while CVD uses chemical processes.

3.1.1 PVD methods. Many of the common PVD synthesis techniques such as RF sputtering, direct current (DC) sputtering, thermal evaporation, thermal oxidation, molecular beam epitaxy (MBE), pulse vapour deposition (PLD) and electron beam epitaxy (EBE) have been used for the deposition of nanostructured $\mathrm{Cu}_{x} \mathrm{O}$. A PVD process is purely physical, starting with either $\mathrm{Cu}_{x} \mathrm{O}$ or $\mathrm{Cu}$ as the source material in the form of a solid target or powder, which is evaporated or sputtered with the application of ion bombardment, thermal heating, electron beam impingement or laser irradiation.

3.1.1.1 Sputtering. Amongst the PVD techniques, sputtering has, thus far, been the most common technique to synthesize thin film $\mathrm{Cu}_{x} \mathrm{O}$ due to the ease of control over the deposition parameters. The as-synthesized films usually exhibit a nanometer-sized tightly packed columnar structure..$^{\mathbf{1 2 0 - 1 2 5}}$ Sputtering is a process in which atoms are ejected from a solid target material by bombarding it with energetic particles. It offers a high degree of control over a film's crystallinity and stoichiometry. The crystallinity, grain dimension and stoichiometry of the copper oxide films can be controlled by varying the sputtering parameters such as applied power, oxygen flow rate, 
oxygen partial pressure and concentration as well as annealing temperature. ${ }^{32,120-122,124-128}$ For example, Chu et al. reported crystallite sizes of $\mathrm{Cu}_{2} \mathrm{O}$ thin films varying from 16.8 to $8.8 \mathrm{~nm}$ when oxygen partial pressures increased from $1.1 \times 10^{-3}$ to $1.8 \times 10^{-3}$ Torr. This indicated that the higher the oxygen partial pressure, the smaller the crystallite size in the nanocrystalline $\mathrm{Cu}_{2} \mathrm{O}$ thin films. ${ }^{120}$ In contrast, Elfadill et al. reported that the crystallite size of $\mathrm{CuO}$ increased from 12 to $24 \mathrm{~nm}$ as the oxygen pressure increased. ${ }^{\mathbf{1 2 5}}$

Generally in an oxygen rich sputtering chamber, at relatively low sputtering powers, only a small number of $\mathrm{Cu}$ atoms are sputtered, which effectively react with oxygen in the plasma, resulting in the deposition of films with high oxygen content such as $\mathrm{CuO}$ films. Conversely, $\mathrm{Cu}_{2} \mathrm{O}$ films are formed at high sputtering powers, due to a large number of sputtered $\mathrm{Cu}$ atoms. ${ }^{\mathbf{1 2 2 , 1 2 6}}$ However, relatively high sputtering powers can also adversely affect the stoichiometry of the films, resulting in the presence of unreacted metallic copper and undesirable stoichiometric ratios between copper and oxygen. ${ }^{\mathbf{1 2 2}}$

Although $\mathrm{Cu}_{4} \mathrm{O}_{3}$ was discovered during the late 1870s, the synthesis of single phase $\mathrm{Cu}_{4} \mathrm{O}_{3}$ thin films has rarely been reported. Pierson et al. and Richthofen et al. have successfully demonstrated the synthesis of single $\mathrm{CuO}, \mathrm{Cu}_{2} \mathrm{O}$ and $\mathrm{Cu}_{4} \mathrm{O}_{3}$ phases by varying the oxygen flow rate using a reactive magnetron sputtering technique..$^{32,128}$ They used a $\mathrm{Cu}$ target with the
RF power maintained at $600 \mathrm{~W}$. It was suggested that conductive $\mathrm{Cu}$-rich copper oxide $\left(\mathrm{Cu}_{4} \mathrm{O}_{3}\right)$ thin films tend to form at an oxygen flow rate $R\left(\mathrm{O}_{2}\right)<30 \%$, whereas insulator O-rich copper oxide $(\mathrm{CuO})$ thin films tend to form at $R\left(\mathrm{O}_{2}\right) \geq 30 \% .{ }^{129}$ This is in contrast to the work of Blobaum et al. who also successfully synthesized $\mathrm{Cu}_{4} \mathrm{O}_{3}$ films via sputtering, but with a $\mathrm{CuO}$ target and at a lower sputtering power of $200 \mathrm{~W} .{ }^{\mathbf{1 2 7}}$

3.1.1.2 Thermal evaporation. Deposition of $\mathrm{Cu}_{x} \mathrm{O}$ films using thermal evaporation is achieved by vaporizing a source material of $\mathrm{Cu}$ or $\mathrm{Cu}_{x} \mathrm{O}$ (in either powder or condensed form) using heat either in a vacuum or in a controlled gaseous environment at a low pressure..$^{25,45,130-133}$ The vaporized $\mathrm{Cu}$ or $\mathrm{Cu}_{x} \mathrm{O}$ that emanates from the material source interacts with the gas molecules in the environment of the deposition chamber before condensing onto a substrate. Processing parameters such as evaporation temperature, substrate temperature, substrate type, gas environment and pressure all play important roles in achieving the desirable $\mathrm{Cu}_{x} \mathrm{O}$ thin films. ${ }^{\text {25,131,134 }}$ It has been reported that the as-synthesized $\mathrm{Cu}_{x} \mathrm{O}$ films from these methods are usually compact thin films, which are textured by nanocrystallites (25$30 \mathrm{~nm}) .^{25,45,132,133}$

3.1.1.3 Thermal oxidation. Thermal oxidation techniques offer a simple, convenient and fast method to synthesize nanostructured $\mathrm{Cu}_{x} \mathrm{O}$ with various morphologies including nanowires, nanoribbons and nanorods. ${ }^{135-139}$ In this method

(i)

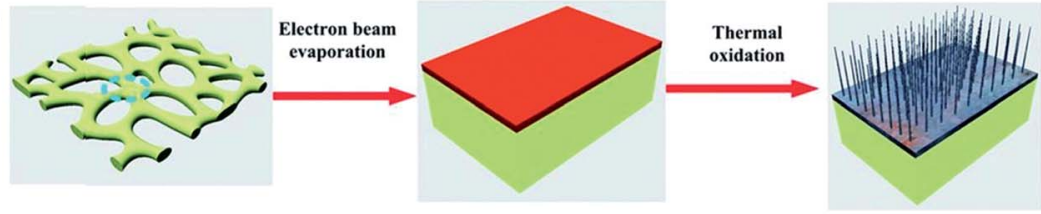

Nickel foam

Cu film on

nickel foam

CuO nanowires o

(ii)

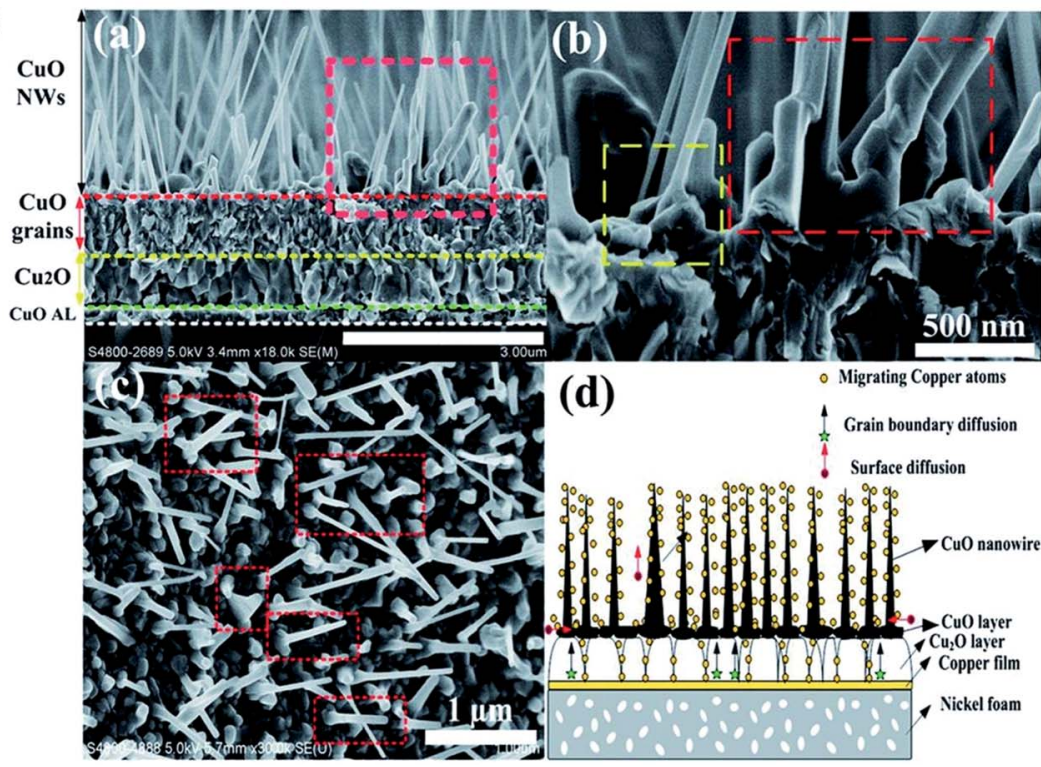

Fig. 6 (i) Schematic illustration of the synthesis process for CuO nanowires on nickel foam. (ii) (a) Cross-sectional view of CuO nanowires synthesized on the $\mathrm{CuO}$ adhesion layer (AL)/Si substrate, (b) magnified view from the nanowire root region marked by the red dashed square, (c) top-view of $\mathrm{CuO}$ nanowires synthesized on Ni foam and (d) illustration of the mechanism for CuO nanowire growth. Reproduced from ref. 148 with permission from The Royal Society of Chemistry. 
nanostructured $\mathrm{Cu}_{x} \mathrm{O}$ is directly grown on the surface of a $\mathrm{Cu}$ substrate. ${ }^{137,138,140}$ Thermal oxidation is performed by simply heating a $\mathrm{Cu}$ substrate to a high temperature (typically between 200 and $800{ }^{\circ} \mathrm{C}$ ) in an oxygen rich environment..$^{135,137,138,141-143}$ Generally, the morphology and stoichiometry of the $\mathrm{Cu}_{x} \mathrm{O}$ can be controlled by tuning the deposition parameters. For instance, the diameter and density of $\mathrm{Cu}_{x} \mathrm{O}$ nanowires can be altered by changing the oxidation temperature. ${ }^{\mathbf{1 4 4}}$ However, very high oxidation temperatures $\left(>900{ }^{\circ} \mathrm{C}\right)$ are not suitable for nanowire formation as $\mathrm{Cu}_{x} \mathrm{O}$ nanostructures can be fused together, as observed by Huang et al. ${ }^{\mathbf{1 4 5}}$ Valladares et al. have studied the effect of oxidation temperature in altering the stoichiometry of the $\mathrm{Cu}_{x} \mathrm{O}$ films. They have observed that pure $\mathrm{Cu}_{2} \mathrm{O}$ films are obtained at $200{ }^{\circ} \mathrm{C}$, whereas $\mathrm{CuO}$ films are obtained above $300{ }^{\circ} \mathrm{C}^{\mathbf{1 4 3}}$

Unfortunately, mechanical adhesion between the as-deposited nanostructured $\mathrm{Cu}_{x} \mathrm{O}$ and the substrates synthesized by the thermal oxidation method is very weak. ${ }^{143,146-149}$ Cracking and flaking of the $\mathrm{Cu}_{x} \mathrm{O}$ films or even exfoliation from the substrates poses a big challenge which severely affects the properties and practical applications of the nanostructured $\mathrm{Cu}_{x} \mathrm{O}$. Several methods have been proposed to alleviate the cracking and flaking problem including pre-deposition of a $\mathrm{ZnO}$ layer on copper foil, ${ }^{150}$ synthesis of $\mathrm{CuO}$ nanowires on other foreign substrates such as silicon ${ }^{147,151}$ or glass ${ }^{152}$ and synthesis of $\mathrm{CuO}$ nanowires on porous substrates such as the porous copper substrate $^{\mathbf{1 4 9}}$ or nickel foam ${ }^{\mathbf{1 4 8}}$ as shown in Fig. 6. Zhang et al. have successfully demonstrated non-cracked and flaked $\mathrm{CuO}$ nanowires synthesized on porous copper substrates. The porous substrates managed to reduce thermal stress during the oxidation process and as a result eliminate cracking and flaking issues. ${ }^{149}$

3.1.1.4 Other PVD methods. Apart from the aforementioned vapour phase methods, $\mathrm{PLD}^{153-157}$ and $\mathrm{EBE}^{158-161}$ deposition techniques are the other alternatives available for synthesizing $\mathrm{Cu}_{x} \mathrm{O}$ films. It has been reported that the as-synthesized $\mathrm{Cu}_{x} \mathrm{O}$ from these methods are usually compact thin films, which are textured by nanocrystallites $(10-800 \mathrm{~nm})$. The dimensions of the crystallites are significantly affected by the oxygen pressure and substrate temperature which were identified as being the two most important parameters. ${ }^{154,155}$

\subsection{CVD methods}

CVD processes have become the popular deposition techniques owing to their inherent flexibility and potential to tailor the $\mathrm{Cu}_{x} \mathrm{O}$ phase composition by simply varying the operating conditions and precursors. Many forms of CVD have been used for depositing different $\mathrm{Cu}_{x} \mathrm{O}$ stoichiometries, including atmospheric pressure CVD, ${ }^{13,162,163}$ aerosol assisted CVD, ${ }^{164-167}$ and plasma assisted CVD. ${ }^{168}$ Such films are typically of a compact structure, consisting of micro- or nanometer-sized grains.

Generally, precursors such as bis-(2,4-pentanedionato) copper(II) or $\mathrm{Cu}(\mathrm{acac})_{2}$ (acac $=$ acetylacetonate) are used due to their high sublimation rate (activation energy of $105.6 \mathrm{~kJ} \mathrm{~mol}^{-1}$ ) and low sublimation temperature between 140 and $190{ }^{\circ} \mathrm{C} .{ }^{\mathbf{1 6 2}}$ Valtierra et al. have demonstrated the synthesis of nanostructured
$\mathrm{Cu}_{4} \mathrm{O}_{3}$ and $\mathrm{CuO}$ thin films with a crystallite size of 6.5 to $8.4 \mathrm{~nm}$ on fiberglass substrates using $\mathrm{Cu}(\text { acac })_{2}$ as a precursor and oxygen as a carrier-reactant gas via atmospheric pressure CVD. ${ }^{162}$ The deposition temperature of $\mathrm{CuO}$ and $\mathrm{Cu}_{4} \mathrm{O}_{3}$ was recorded as $315{ }^{\circ} \mathrm{C}$ and $345{ }^{\circ} \mathrm{C}$, respectively. In addition, thin films of $\mathrm{Cu}_{2} \mathrm{O}$ have also been synthesized on fiberglass substrates using a similar technique and precursors by Ortiz et al. at a deposition temperature of $320{ }^{\circ} \mathrm{C} .{ }^{163}$

However, precursors such as $\mathrm{Cu}(\mathrm{acac})_{2}, \mathrm{Cu}(\mathrm{dpm})_{2}(\mathrm{dpm}=$ dipivaloylmethanate) and $\mathrm{Cu}(\mathrm{hfa})_{2} \quad$ (hfa $=$ hexafluoroacetylacetonate) may present drawbacks in terms of poor thermal characteristics, reduced shelf life, halide incorporation or instability upon prolonged utilization due to aging phenomena. ${ }^{\mathbf{1 6 9}}$ Therefore, a second generation of adducts of the type $\mathrm{M}(\mathrm{hfa})_{2} \cdot$ tetramethylethylenediamine(TMEDA) $(\mathrm{M}=\mathrm{Cu}(\mathrm{I})$ or $\mathrm{Cu}(\mathrm{II})$ ) have been successfully adopted as alternative precursors. ${ }^{169}$ They have favourable properties in terms of improved long-term stability and volatility with respect to conventional $\beta$ diketonate. ${ }^{13,169}$ Barreca et al. were the first group to successfully demonstrate the deposition of nanostructured $\mathrm{CuO}$ and $\mathrm{Cu}_{2} \mathrm{O}$ using the $\mathrm{Cu}(\mathrm{hfa})_{2}$ adduct with TMEDA via CVD. ${ }^{169}$ They successfully demonstrated morphological evolution from continuous films to $1 \mathrm{D}$ hyperbranched nanostructures. ${ }^{169}$

Spray pyrolysis is a typical aerosol-assisted chemical vapour deposition, which is utilized in the glass industry and in solar cell production to deliver film coatings of various thicknesses. ${ }^{34}$ This method has the benefit of forming large-scale thin films by using a simple apparatus that can lead to increased productivity. Moreover, the film thickness and stoichiometry are easy to control and the resulting films are generally dense. ${ }^{\mathbf{1 6 5 , 1 6 6}}$ During film deposition, the precursor's solution is pumped to an atomizer, and then sprayed onto heated substrates. Subsequently the droplets undergo evaporation, solute condensation and thermal decomposition, which results in film formation. ${ }^{34}$ The composition of these thin films is highly dependent on the solvent, morphology of the substrate as well as the deposition temperatures. ${ }^{\mathbf{1 6 4 , 1 7 0}}$

$\mathrm{Cu}_{x} \mathrm{O}$ films generated by the spray pyrolysis method are generally produced from copper acetate or copper nitrate as precursors dissolved in alcohol based solutions such as ethanol, propanol or methanol. ${ }^{\mathbf{1 6 4 , 1 6 6 , 1 7 0 , 1 7 1}}$ Alcohols are used to increase the wettability of the sprayed solution on the substrate and to improve the homogeneity of the deposited films. ${ }^{\mathbf{1 6 5}}$ It has been reported that $\mathrm{Cu}_{x} \mathrm{O}$ nanostructures are formed with the addition of glucose or sucrose to the solution. ${ }^{\mathbf{1 6 5 , 1 6 7}}$ These sugars are used as reducing agents in the precipitation of the $\mathrm{Cu}_{x} \mathrm{O}$ nanostructures. ${ }^{165}$ Waser et al. demonstrated synthesis of $\mathrm{CuO}$ nanoparticles via flame spray pyrolysis with various diameters from 6 to $50 \mathrm{~nm}$ by varying the precursor solution and the oxygen flow rate. ${ }^{172}$

Apart from $\mathrm{CuO}$ and $\mathrm{Cu}_{2} \mathrm{O}$ films, $\mathrm{Cu}_{4} \mathrm{O}_{3}$ films can also be obtained via spray pyrolysis techniques. Albores et al. have successfully demonstrated the deposition of $\mathrm{Cu}_{4} \mathrm{O}_{3}$ films on $\mathrm{ZnO}$ nanorods. ${ }^{170}$ The formation of $\mathrm{Cu}_{4} \mathrm{O}_{3}$ films is a gradual process. Initially, the possible lattice matching of $\mathrm{ZnO}$ and $\mathrm{CuO}$ promotes the growth of $\mathrm{CuO}$. In the presence of methanol, at elevated temperatures, the $\mathrm{Cu}^{2+}$ in $\mathrm{CuO}$ is reduced to $\mathrm{Cu}^{1+}$ forming $\mathrm{Cu}_{2} \mathrm{O}$ as: ${ }^{170}$ 

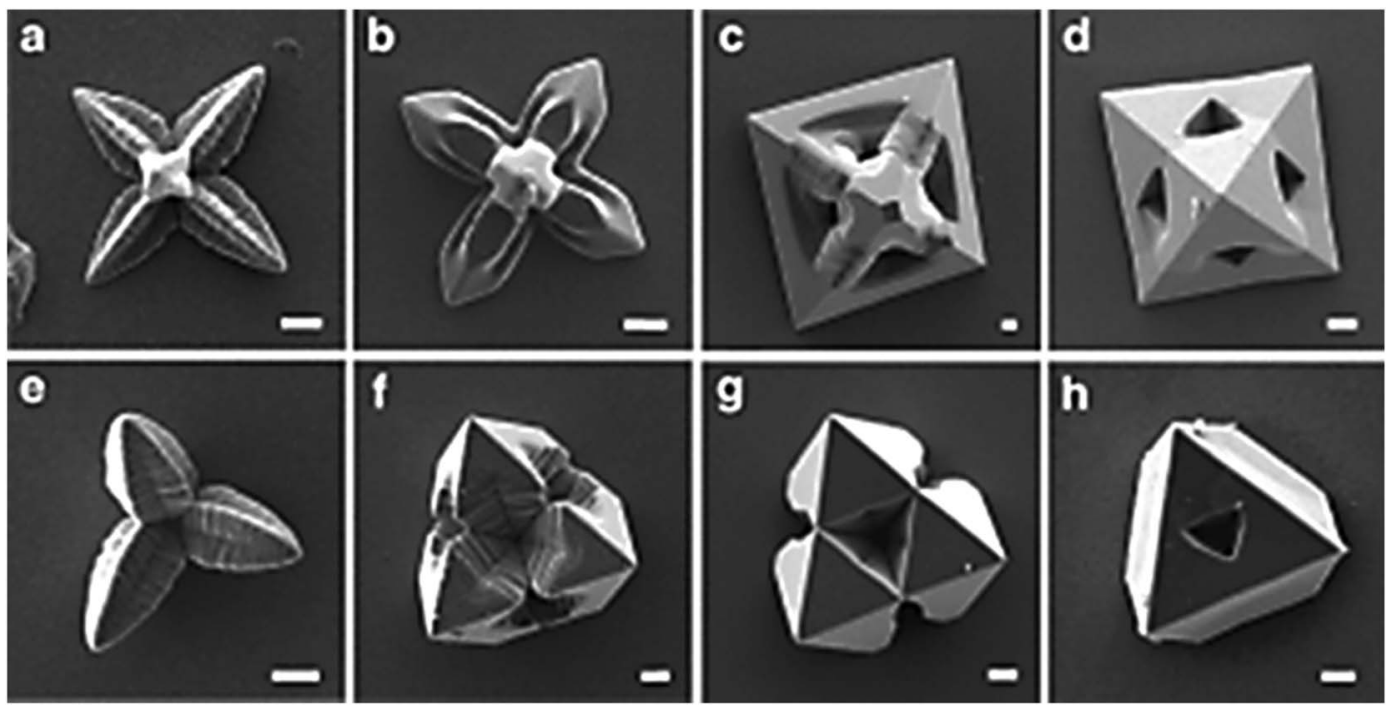

Fig. 7 SEM images of deposited octahedral $\mathrm{Cu}_{2} \mathrm{O}$ crystals that display systematically varying degrees of branching with (100) planes parallel to the substrate $(\mathrm{a}-\mathrm{d})$ and with (111) planes parallel to the substrate $(\mathrm{e}-\mathrm{h})$. These crystals were obtained at a constant temperature $\left(60{ }^{\circ} \mathrm{C}\right)$ and concentration of $\mathrm{Cu}^{2+}(0.02 \mathrm{M})$ and by applying deposition conditions of $0.10 \mathrm{~mA} \mathrm{~cm}{ }^{-2} \leq 1 \leq 0.12 \mathrm{~mA} \mathrm{~cm}^{-2}$ and $0.08 \mathrm{~V} \leq E \leq 0.12 \mathrm{~V}$. All figures have scale bars of $1 \mu \mathrm{m}$. Reprinted with permission from (M. J. Siegfried and K. S. Choi, Angew. Chem. Int. Ed., 2005, 44, 3218-3223) copyright (2012) by WILEY-VCH Verlag GmbH \& Co. KGaA, Weinheim.

$$
\mathrm{CH}_{3} \mathrm{OH}_{(\mathrm{g})}+6 \mathrm{CuO} \rightarrow 3 \mathrm{Cu}_{2} \mathrm{O}+\mathrm{CO}_{2(\mathrm{~g})}+2 \mathrm{H}_{2} \mathrm{O}_{(\mathrm{g})}
$$

Then at these elevated temperatures, the solid reaction between $\mathrm{CuO}$ and $\mathrm{Cu}_{2} \mathrm{O}$ results in paramelaconite phase formation which can be described by: ${ }^{\mathbf{1 7 0}}$

$$
2 \mathrm{CuO}+\mathrm{Cu}_{2} \mathrm{O} \rightarrow \mathrm{Cu}_{4} \mathrm{O}_{3}
$$

\subsection{Liquid phase synthesis}

Liquid phase techniques include methods such as electrodeposition, hydrothermal/solvothermal and sol-gel. These methods are generally chosen due to their low capital cost and better control of the material's morphology in comparison to vapour phase deposition techniques as well as the deposition at relatively low temperatures, which is crucial for low-heattolerant substrates. Among a variety of liquid phase synthesis methods, hydrothermal/solvothermal and chemical precipitation techniques have been widely used to synthesize $\mathrm{Cu}_{x} \mathrm{O}$ nanostructures.

3.3.1 Electrodeposition. Electrodeposition is a process in which metal ions in an electrolyte are reduced at a conducting electrode under potential control. The process uses electrical current to reduce $\mathrm{Cu}^{2+}$ ions from an aqueous solution. The electrolyte generally contains a mixture of a $\mathrm{Cu}$ salt such as copper sulphate, copper acetate or copper nitrate and a chelating agent such as lactic acid, ammonium nitrate, amino acids or tartaric acids..$^{\mathbf{2 9 1 7 3 - 1 7 7}}$ The deposition is carried out in an alkaline environment with the addition of sodium hydroxide or ammonia to control the $\mathrm{pH}$ level. The electrodeposition technique is commonly used for depositing $\mathrm{CuO}$ and $\mathrm{Cu}_{2} \mathrm{O}$ films. ${ }^{3,29,173-175,177-180}$ Such films are typically of a compact structure, consisting of micro- or nanometer-sized grains. The stoichiometry of the electrodeposited films is very much dependent on the type of the chelating agent and applied potential used during the electrodeposition process. Generally, $\mathrm{CuO}$ films are obtained upon the application of a positive voltage/current bias, where oxidation of $\mathrm{Cu}$ is expected and this process is well known as anodic electrodeposition. Inversely, $\mathrm{Cu}_{2} \mathrm{O}$ films are deposited at a negative bias, in which the reduction process occurs (cathodic electrodeposition). ${ }^{\mathbf{1 7 3 , 1 7 4 , 1 8 1}}$

Synthesis of $\mathrm{CuO}$ films via anodic electrodeposition in an alkaline solution containing copper(II) nitrate, ammonium nitrate and ammonia has been reported by Izaki et al. at $+0.9 \mathrm{~V}$ vs. $\mathrm{Ag} / \mathrm{AgCl} .{ }^{174}$ Sasano et al. demonstrated that $\mathrm{CuO}$ films formed by applying potential pulses are more crystalline than the ones deposited using a constant potential. ${ }^{176}$ The mechanism for the electrodeposition of $\mathrm{CuO}$ films is outlined in eqn (7)-(10). The reaction starts via electrolysis of water to generate oxygen and protons (reaction (7)). Consequently, these protons react with ammonia $\mathrm{Cu}$ (II) complexes to yield free $\mathrm{Cu}$ (II) ions in the vicinity of a substrate's surface (reaction (8)). The free $\mathrm{Cu}$ (II) ions are then hydrolyzed to form $\mathrm{CuO}$ films on the substrate (reactions (9) and (10)). ${ }^{174,181}$

$$
\begin{gathered}
2 \mathrm{H}_{2} \mathrm{O} \rightarrow \mathrm{O}_{2}+4 \mathrm{H}^{+}+4 \mathrm{e}^{-} \\
\mathrm{Cu}\left(\mathrm{NH}_{3}\right)_{4}^{2+}+4 \mathrm{H}^{+} \rightarrow \mathrm{Cu}^{2+}+4 \mathrm{NH}_{4}{ }^{+} \\
\mathrm{Cu}^{2+}+2 \mathrm{OH}^{-} \rightarrow \mathrm{Cu}(\mathrm{OH})_{2} \\
\mathrm{Cu}(\mathrm{OH})_{2} \rightarrow \mathrm{CuO}+\mathrm{H}_{2} \mathrm{O}
\end{gathered}
$$

Similarly, syntheses of $\mathrm{Cu}_{2} \mathrm{O}$ films have been reported via cathodic electrodeposition using an alkaline aqueous solution containing copper(II) sulphate or copper(II) acetate and lactic acid as the chelating agent. ${ }^{\mathbf{1 0 , 1 7 3 , 1 7 5 , 1 7 9 , 1 8 0 , 1 8 2}}$ Zoolfakar et al. have 
demonstrated the electrodeposition of $\mathrm{Cu}_{2} \mathrm{O}$ films onto $\mathrm{ZnO}$ for forming heterojunction solar cells. ${ }^{173}$ The electrodeposition process was carried out at $-0.55 \mathrm{~V} v s$. $\mathrm{Ag} / \mathrm{AgCl}$. $\mathrm{Cu}_{2} \mathrm{O}$ was formed according to the following electrochemical reaction. ${ }^{175}$

$$
2 \mathrm{Cu}^{2+}+2 \mathrm{e}^{-}+2 \mathrm{OH}^{-} \rightarrow \mathrm{Cu}_{2} \mathrm{O}+\mathrm{H}_{2} \mathrm{O}
$$

Apart from depositing thin films of $\mathrm{Cu}_{x} \mathrm{O}$, electrodeposition techniques have been used to synthesize various morphologies of nanostructured $\mathrm{CuO}$ and $\mathrm{Cu}_{2} \mathrm{O}$ including leaf-like, ${ }^{183}$ nanospindles ${ }^{184}$ nanocubes, ${ }^{185}$ nanorod ${ }^{186}$ and cauliflower-like. ${ }^{187}$ Interestingly, Siegfried and Choi have demonstrated a new level of tuning and engineering the morphology of $\mathrm{Cu}_{2} \mathrm{O}$ crystals via the electrodeposition technique. ${ }^{188,189}$ They manipulated deposition parameters such as potential and current to engineer $\mathrm{Cu}_{2} \mathrm{O}$ crystals as illustrated in Fig. $7 .{ }^{189}$

3.3.2 Hydrothermal and solvothermal. Hydrothermal and solvothermal processes are facile and cost-effective deposition techniques. They have the capability of producing nanostructured $\mathrm{Cu}_{x} \mathrm{O}$ of different morphologies including nanodendrites, ${ }^{190}$ nanowires, ${ }^{71}$ nanorings,${ }^{191}$ nanorods, ${ }^{192-195}$ nanoribbons, ${ }^{191,194}$ nanotubes, ${ }^{192}$ microspheres ${ }^{194,196}$ and macrowhiskers. ${ }^{197}$ (Fig. 8).

The synthesis of nanostructured $\mathrm{Cu}_{x} \mathrm{O}$ has been hydrothermally achieved using various precursors such as copper(II) chloride, copper(II) acetate or copper(II) sulphate. Generally, a lower concentration of $\mathrm{Cu}(\mathrm{OH})_{4}{ }^{2-}$ precursors favours tubular formation, whereas a higher concentration leads to rodlike morphologies. ${ }^{192,194}$ In most cases, the hydrothermal synthesis of $\mathrm{Cu}_{x} \mathrm{O}$ starts with the preparation of a solution that contains copper salts, sodium hydroxide and solvents, typically deionized water. Such a solution is then kept at an elevated temperature $\left(100-300{ }^{\circ} \mathrm{C}\right)$ for a certain period of time, allowing the nucleation and growth of $\mathrm{Cu}_{x} \mathrm{O}$ crystallites.

Solvothermal methods are almost identical to hydrothermal methods except that organic solvents are used instead of water. ${ }^{198,199}$ In comparison with the hydrothermal method, the solvothermal method exhibits many advantages such as easier morphological control, free foreign anions and macroscopic quantity. ${ }^{200,201}$ Recent reports have shown that the high-aspectratio of $\mathrm{Cu}_{x} \mathrm{O}$ nanostructures can be synthesized via solvothermal methods. ${ }^{202-205}$ Zhao et al. have demonstrated a facile method to synthesize pure polycrystalline $\mathrm{Cu}_{4} \mathrm{O}_{3}$ microspheres using copper(II) nitrate as the precursor in the presence of $N, N$ dimethylformamide and ethanol. ${ }^{201}$ They have successfully manipulated the $\mathrm{CuO} / \mathrm{Cu}_{2} \mathrm{O}$ stoichiometry ratio to generate $\mathrm{Cu}_{4} \mathrm{O}_{3}$ films with the reaction of $\left(2 \mathrm{CuO}+\mathrm{Cu}_{2} \mathrm{O} \rightarrow \mathrm{Cu}_{4} \mathrm{O}_{3}\right)$ in a closed system. ${ }^{201}$

3.3.3 Solution-based chemical precipitation methods. In most cases, the chemical precipitation synthesis of $\mathrm{CuO}$ nanoparticles starts with the preparation of a solution that contains copper salts, sodium hydroxide and solvents, typically deionized water. In order to avoid agglomeration of the CuO nanoparticles, an external energy such as ultrasonic or high pressure needs to be applied during the synthesis process. Zhu et al. prepared highly dispersed $\mathrm{CuO}$ nanoparticles of $6 \mathrm{~nm}$ with various morphologies including spherical, ellipsoidal and
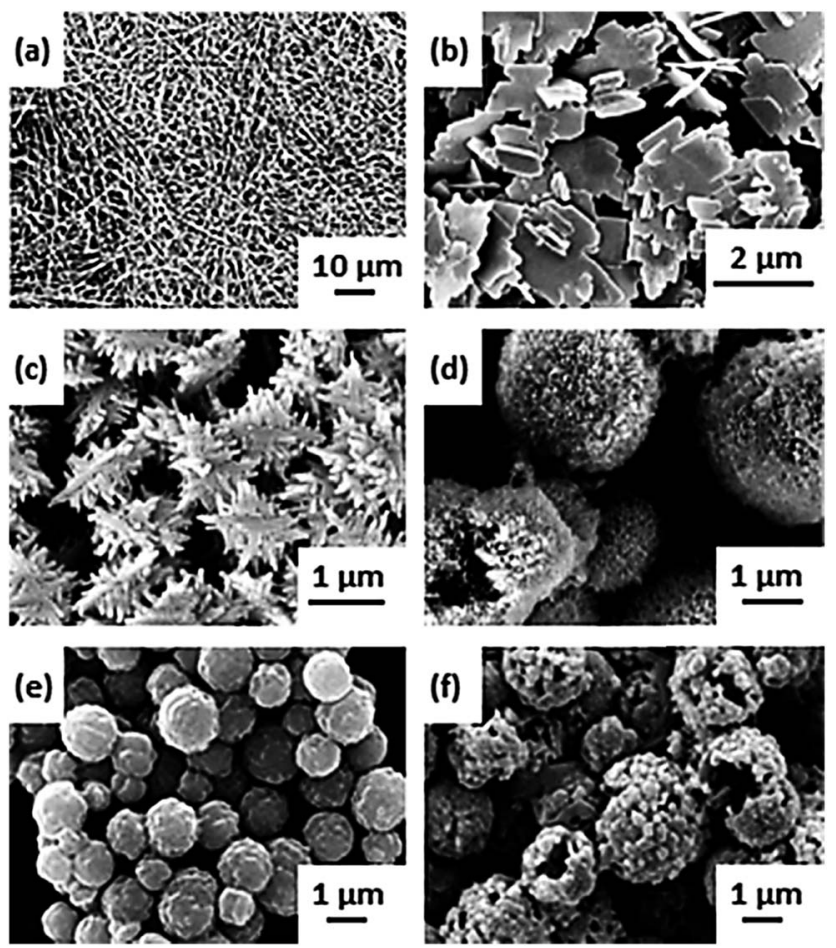

Fig. 8 SEM images of various morphologies via hydrothermally/solvothermally synthesized (a) $\mathrm{Cu}_{2} \mathrm{O}$ nanowires synthesized at $180{ }^{\circ} \mathrm{C}$ in copper(II) acetate aqueous solution with pyrrole, (b) $\mathrm{CuO}$ flake-like synthesized at $200{ }^{\circ} \mathrm{C}$ in copper(II) sulphate aqueous, (c) $\mathrm{CuO} / \mathrm{Cu}_{2} \mathrm{O}$ dendrite-like synthesized at $200^{\circ} \mathrm{C}$ in copper(I) sulphate aqueous with $10 \mathrm{ml}$ ethylene glycol (EG), (d) $\mathrm{CuO} / \mathrm{Cu}_{2} \mathrm{O}$ flower-like synthesized at $200{ }^{\circ} \mathrm{C}$ in copper(॥) sulphate aqueous with $20 \mathrm{ml} \mathrm{EG}$, and $\mathrm{CuO} / \mathrm{Cu}_{2} \mathrm{O}$ composite hollow microspheres obtained in a copper(॥) acetate aqueous solution at $200^{\circ} \mathrm{C}$ for (e) 1 hour and (f) 5 hours. Reprinted with permission from (a) (Y. W. Tan, X. Y. Xue, Q. Peng, H. Zhao, T. H. Wang and Y. D. Li, Nano Lett., 2007, 7, 3723-3728) copyright (2007) American Chemical Society, (b-d) (S. Z. Li, H. Zhang, Y. J. Ji and D. R. Yang, Nanotechnology, 2004, 15, 1428-1432) copyright (2004) by IOP Publishing Ltd, (e and f) (H. Yu, J. Yu, S. Liu and S. Mann, Chem. Mater., 2007, 19, 4327-4334) copyright (2007) American Chemical Society.

needle-shaped $\mathrm{CuO}^{206} \mathrm{Wu}$ et al. prepared $\mathrm{CuO}$ nanoparticles with different sizes and morphologies in organic solvents such as dimethylacetamide (DMAC). ${ }^{207}$ They found that the nucleation and growth kinetics of $\mathrm{CuO}$ nanoparticles can be tuned by varying the processing parameters including the volume ratio of DMAC and water, increasing the temperature of the solution and the molar ratio of $\mathrm{Cu}^{2+}$ and $\mathrm{OH}^{-} .{ }^{207}$ Apart from nanoparticles, chemical precipitation synthesis has commonly been used to synthesize different morphologies of $\mathrm{CuO}$ including nanowires, ${ }^{208-210}$ nanoribbons, ${ }^{211}$ flower-like, ${ }^{212,213}$ hierarchical nanochains ${ }^{214}$ and nanosheets. ${ }^{215,216} \mathrm{~A}$ recent comprehensive review on nanostructured $\mathrm{CuO}$ via the solution-based chemical precipitation technique is found elsewhere. ${ }^{1}$

There are many reports of synthesis of nanostructured $\mathrm{Cu}_{2} \mathrm{O}$ via chemical precipitation. ${ }^{53,217-224}$ Gou et al. demonstrated a synthesis of highly uniform and monodisperse $\mathrm{Cu}_{2} \mathrm{O}$ nanocubes. The process involved the use of sodium ascorbate to reduce $\mathrm{Cu}(\mathrm{II})$ salts in water, in the presence of a surfactant and $\mathrm{NaOH}$. The nanocube dimensions were tuned by varying the 
concentration of the surfactant. ${ }^{217}$ Zhang et al. reported synthesis of monodisperse $\mathrm{Cu}_{2} \mathrm{O}$ and $\mathrm{CuO}$ nanospheres. It has also been shown that by modulating the concentration of solvent, the diameter, crystallization and monodispersity of $\mathrm{Cu}_{2} \mathrm{O}$ nanospheres can be kinetically controlled. ${ }^{53}$ Interestingly, various groups have reported a facile method for the synthesis of $\mathrm{Cu}_{2} \mathrm{O}$ nanocrystals with systematic shape evolution (Fig. 9). ${ }^{\text {220-223 }}$ Recently, Susman et al. demonstrated precise morphology control of $\mathrm{Cu}_{2} \mathrm{O}$ nanocrystals covering the entire range of morphologies from complete cubes, via the intermediate morphologies truncated octahedral, cuboctahedra and truncated cubes, to complete octahedral. ${ }^{220}$ The highly effective morphology control is attributed to competitive adsorption of hydroxide and citrate anions on the [100] and [111] planes of the growing crystallite. ${ }^{220}$

3.3.4 Other film formation methods. A sol-gel process involves the formation of a colloidal solution ( $\mathrm{sol}$ ) from selected chemicals that acts as a precursor for an integrated network (i)

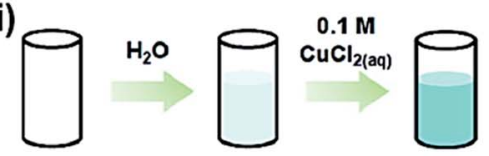

A $\quad 9.4 \mathrm{~mL}$

$0.1 \mathrm{~mL}$

B $\quad 9.2 \mathrm{~mL}$

C $\quad 9.0 \mathrm{~mL}$

D $\quad 8.8 \mathrm{~mL}$

$0.1 \mathrm{~mL}$

$0.1 \mathrm{~mL}$

$0.1 \mathrm{~mL}$

$\left(10^{-3} \mathrm{M}\right)$

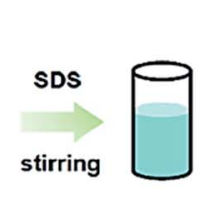

$0.087 \mathrm{~g}$

$0.087 \mathrm{~g}$

$0.087 \mathrm{~g}$

$0.087 \mathrm{~g}$

$\left(3 \times 10^{-2} \mathrm{M}\right)$
$0.2 \mathrm{M}$

$\mathrm{NH}_{2} \mathrm{OH}$

- $\mathrm{HCl}_{(\mathrm{aq})}$

shaking $\square$ for $10 \mathrm{~s}$

$0.25 \mathrm{~mL}$

$0.45 \mathrm{~mL}$

$0.65 \mathrm{~mL}$

$0.85 \mathrm{~mL}$

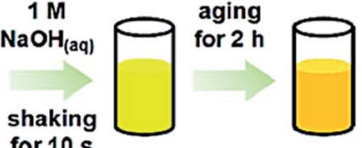

for $10 \mathrm{~s}$

$0.25 \mathrm{~mL}$

$0.25 \mathrm{~mL}$

$0.25 \mathrm{~mL}$

$0.25 \mathrm{~mL}$

$10 \mathrm{~mL}$

total $=10 \mathrm{~mL}$

$10 \mathrm{~mL}$

(ii)
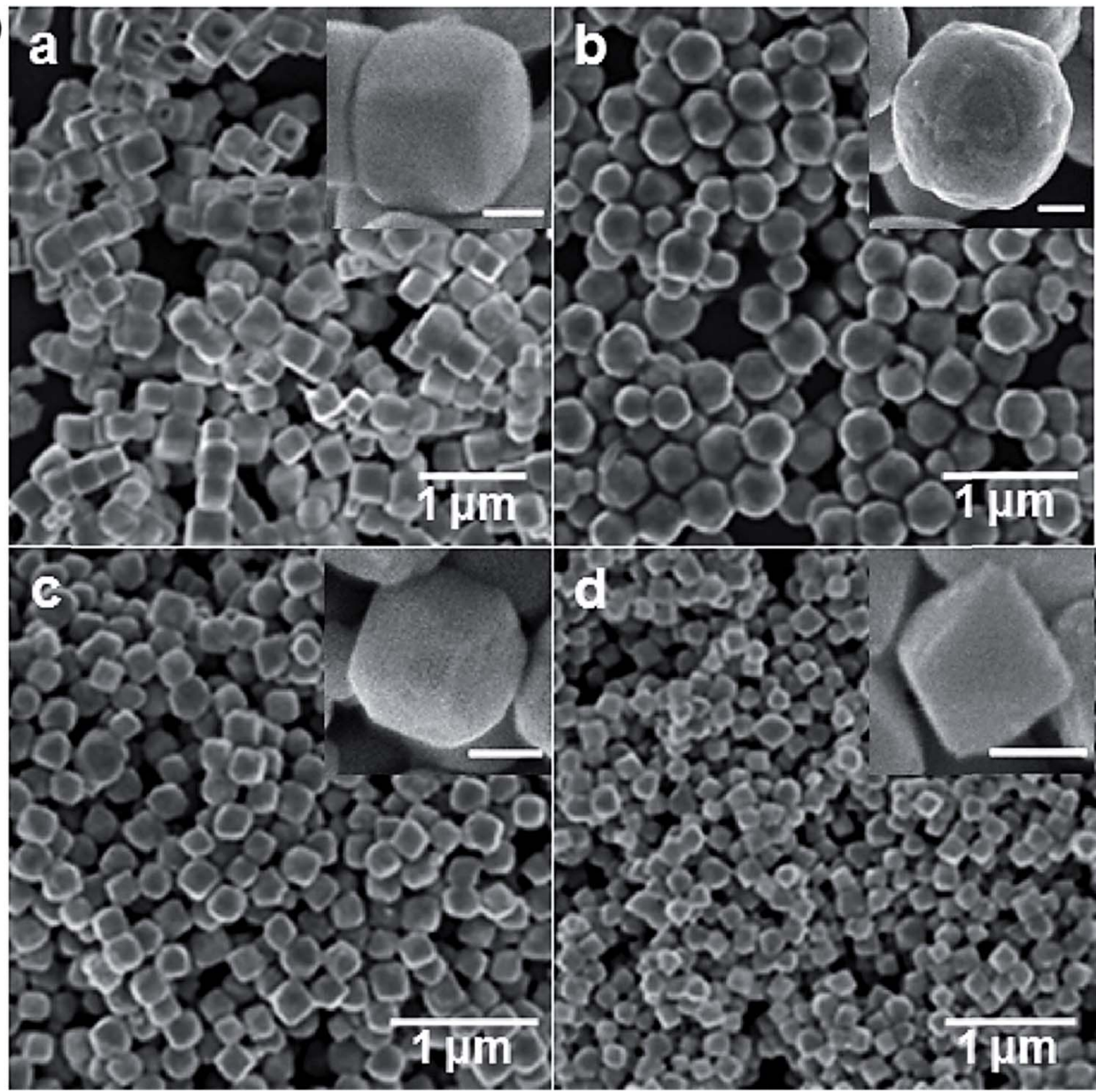

Fig. 9 (i) Schematic illustration of the procedure used for growing $\mathrm{Cu}_{2} \mathrm{O}$ nanocrystals of different shapes. (ii) (a-d) Respective SEM images of the $\mathrm{Cu}_{2} \mathrm{O}$ nanocrystals synthesized in sample containers $\mathrm{A}, \mathrm{B}, \mathrm{C}$ and $\mathrm{D}$ with increasing amounts of $\mathrm{NH}_{2} \mathrm{OH} \cdot \mathrm{HC}$ added to the solutions. The particle morphologies are (a) truncated cubic, (b) cuboctahedral, (c) truncated octahedral and (d) octahedral in shape. Insets show the enlarged views of individual nanocrystals. The scale bars in the insets are $100 \mathrm{~nm}$. Reprinted with permission from (C.-H. Kuo and M. H. Huang, J. Phys. Chem. C, 2008, 112, 18355-18360) copyright (2007) American Chemical Society. 
(gel) of either discrete particles or connected networks. During gelation (aging process), various forms of hydrolysis and polycondensation processes can take place. Film deposition is generally carried out during the gelation process via dipcoating, spin coating or drop-casting onto the substrates. Armelao et al. have reported $\mathrm{Cu}_{x} \mathrm{O}$ thin films via sol-gel synthesis, using ethanolic solutions of copper(II) acetate. ${ }^{25}$ Films were obtained by dip-coating at room temperature in air and were subsequently heat-treated at different temperatures (100-900 $\left.{ }^{\circ} \mathrm{C}\right)$ in oxidizing (air), inert $\left(\mathrm{N}_{2}\right)$ or reducing $\left(4 \% \mathrm{H}_{2}\right.$ in $\mathrm{N}_{2}$ ) atmospheres to observe different crystalline phases of $\mathrm{Cu}_{x} \mathrm{O}$ as a function of the annealing conditions with an average crystallite size lower than $20 \mathrm{~nm} .^{225}$ Ray has also reported a similar technique, however he experimented with methanolic solutions of cupric chloride. ${ }^{226}$ Under atmospheric heat-treatment conditions, Armelao et al. have only managed to observe the $\mathrm{CuO}$ phase with $900{ }^{\circ} \mathrm{C}$ annealing, while Ray has successfully demonstrated the deposition of $\mathrm{CuO}$ and $\mathrm{Cu}_{2} \mathrm{O}$ at $360{ }^{\circ} \mathrm{C}$ and $400-500{ }^{\circ} \mathrm{C}$, respectively. ${ }^{225,226}$

Templating is a modification of the sol-gel synthesis technique and can be very effective for the preparation of $\mathrm{Cu}_{x} \mathrm{O}$ nanowires. ${ }^{\mathbf{1 4 1}}$ Nanostructured $\mathrm{Cu}_{x} \mathrm{O}$ is deposited onto porous templates such as anodic alumina membranes and polycarbonate membranes. ${ }^{227-229}$ Generally, templates are used for assisting the growth of the $\mathrm{Cu}_{x} \mathrm{O}$ by controlling the diameters, lengths and densities of the nanowires. ${ }^{227}$ At the end of the deposition process, the templates must be removed either by chemical reactions ${ }^{229}$ or a selective burn-away at high temperatures. ${ }^{230}$ Consequently, this procedure may prolong the process as well as degrade the quality of the $\mathrm{Cu}_{x} \mathrm{O} \cdot{ }^{141}$

\section{Applications of $\mathrm{Cu}_{x} \mathrm{O}$}

$\mathrm{Cu}_{x} \mathrm{O}$ has been employed for a variety of applications ranging from optical devices to high thermal conductivity systems. In this section, some of the most common applications of $\mathrm{Cu}_{x} \mathrm{O}$ materials are presented. Particular emphasis is placed on the enhancements that can be achieved by exploiting the nanostructured forms of $\mathrm{Cu}_{x} \mathrm{O}$.

\subsection{Solar cells and light emitting diodes}

$\mathrm{Cu}_{x} \mathrm{O}$ films are possible candidates for developing different types of optical devices, including solar cells based on dyesensitized and heterojunction architectures as well as organic light emitting diodes.

The quest and need for a clean and economical energy source have increased interest in the development of solar applications. Amongst various metal oxide materials for solar energy applications, $\mathrm{Cu}_{2} \mathrm{O}$ has attracted increasing interest due to its theoretical power conversion efficiency (PCE) of $18 \%$ and an absorption coefficient higher than single crystalline $\mathrm{Si}^{173,231}$

As described previously $\mathrm{Cu}_{x} \mathrm{O}$ is an intrinsically p-type material. However, self-compensation problems and dopant solubility have inhibited the synthesis of n-type $\mathrm{Cu}_{x} \mathrm{O}$ to produce efficient homojunctions for photovoltaic applications.,72,232 Therefore, heterojunction architectures have been employed with other n-type semiconductors such as $\mathrm{ZnO},{ }^{\mathbf{1 0 , 1 7 3 , 1 7 5}}$ $\mathrm{CdO}^{233} \mathrm{TiO}_{2},{ }^{234-236} \mathrm{Ga}_{2} \mathrm{O}_{3}$ (ref. 237) and GaN. ${ }^{2}$ Amongst the aforementioned n-type semiconductors, $\mathrm{ZnO}$ has been found to be the most stable and exhibit relatively low lattice mismatch of 7.6\% between the (002) $\mathrm{ZnO}$ and (111) $\mathrm{Cu}_{2} \mathrm{O}$ phases., ${ }^{375,177}$ Despite the predicted PCE value of $18 \%$, in practice the $\mathrm{ZnO}-$ $\mathrm{Cu}_{2} \mathrm{O}$ solar systems have yet to reach high efficiencies., ${ }^{3,10,238}$ To date, the highest efficiency ever reported for bilayer $\mathrm{ZnO}-\mathrm{Cu}_{2} \mathrm{O}$ heterojunction solar cells has been $3.83 \% .{ }^{239}$ This is due to the fact that theoretically their intrinsic electronic band structures do not permit an open circuit voltage larger than $0.7 \mathrm{~V} .^{238}$ To date, the largest ever short circuit current that has been reported by Zoolfakar et al. using electrodeposited $\mathrm{ZnO}$ and $\mathrm{Cu}_{2} \mathrm{O}$ films was $12.7 \mathrm{~mA} \mathrm{~cm}^{-2}$ (Fig. 10). ${ }^{173}$

Apart from heterojunction cells, $\mathrm{Cu}_{x} \mathrm{O}$ has also been widely used in dye-sensitized solar cell (DSSC) technology. CuO is commonly used as a blocking layer that prevents recombination reactions by forming a potential barrier between the anode and the electrolyte which enhances the PCE of the device. ${ }^{\mathbf{2 4 0 - 2 4 3}}$ Yet in other experiments, the use of $\mathrm{Cu}_{2} \mathrm{O}$ at the photoanode of a DSSC was found to decrease the overall PCE. ${ }^{244}$ This is due to the dissociation of $\mathrm{Cu}_{x} \mathrm{O}$ in liquid-based electrolytes, inducing numerous extrinsic defects that increase carrier recombination, resulting in photovoltaic performance degradation. ${ }^{244}$

$\mathrm{Cu}_{x} \mathrm{O}$ has also been used in organic light emitting diodes (OLEDs). ${ }^{\mathbf{1 3 4 , 2 4 5}}$ In order to construct efficient OLEDs, it is important to optimize the carrier injection ability at the interface of the active layer and anode materials. The $\mathrm{Cu}_{x} \mathrm{O}$ films are commonly used as hole injection layers (HILs) to lower the hole injection barrier. ${ }^{\mathbf{1 3 4 , 2 4 6 , 2 4 7}} \mathrm{Kim}$ et al. have reported the advantage of using a mixed stoichiometry of $\mathrm{CuO}$ and $\mathrm{Cu}_{2} \mathrm{O}$ for increasing the performance of OLEDs as illustrated in Fig. $11 .{ }^{\mathbf{1 3 4}}$ Mixed stoichiometry of $\mathrm{Cu}_{x} \mathrm{O}$ contains high density of defects such as oxygen vacancies or unbonded oxygen atoms, which act as an

(a)
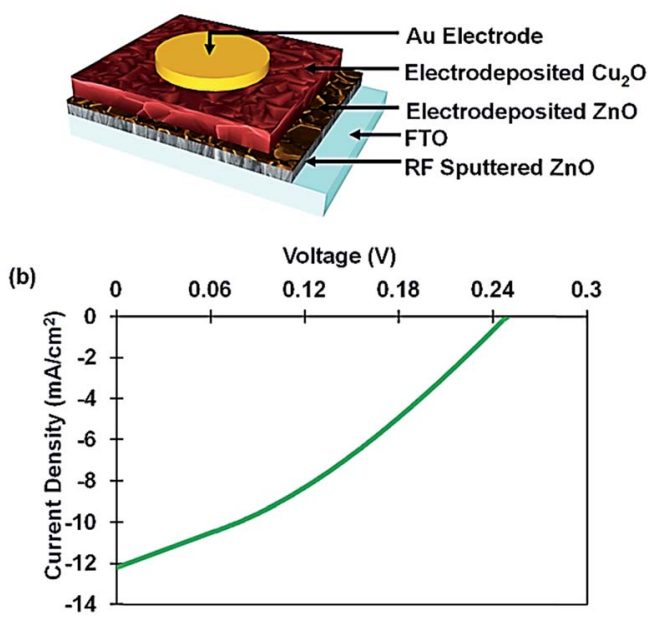

Fig. 10 (a) 3D schematic of the electrodeposited $\mathrm{ZnO}-\mathrm{Cu}_{2} \mathrm{O}$ heterojunction solar cells, (b) $\mathrm{J}-\mathrm{V}$ characteristic curves of $\mathrm{ZnO}-\mathrm{Cu}_{2} \mathrm{O}$ heterojunction solar cells. Reproduced from ref. 173 with permission from The Royal Society of Chemistry. 
extra energy state within the energy gap of the $\mathrm{Cu}_{x} \mathrm{O}$ layer. Interestingly, when the energy levels of these gap states are aligned with the highest occupied molecular orbital (HOMO) level of the hole transporting layer, no potential barrier is produced at the anode interfaces, which can lead to an increase in the hole injection efficiency. ${ }^{\mathbf{1 3 4}}$

\subsection{Photo-catalytic applications}

$\mathrm{Cu}_{x} \mathrm{O}$ is a promising photo-catalyst that is used in many chemical processes, such as organic contamination degradation and water splitting under visible-light irradiation owing to

(i)

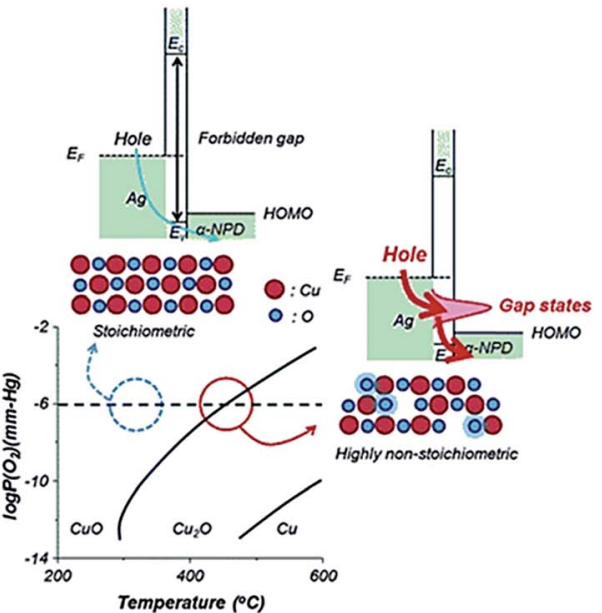

(ii) (a)

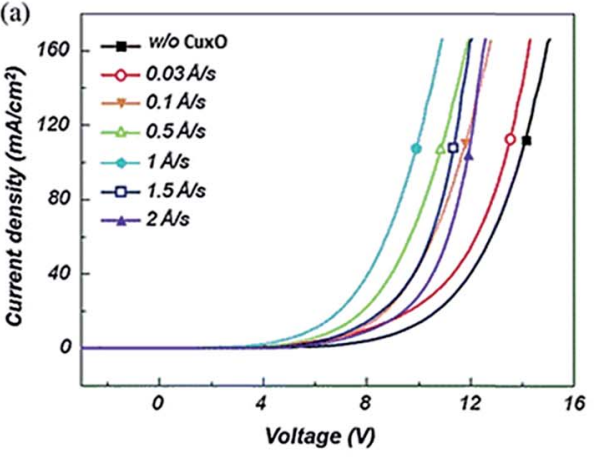

(b)

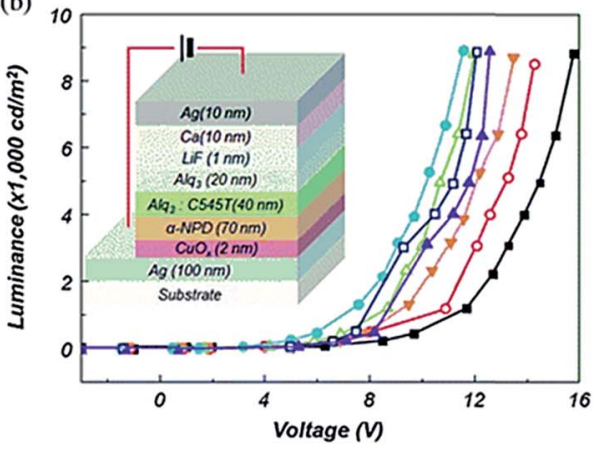

Fig. 11 (i) Phase diagram of a copper-oxygen binary system and the schematic diagram of electronic states and the film structure of stoichiometric and non-stoichiometric $\mathrm{Cu}_{x} \mathrm{O}$, (ii) (a) current-density voltage $(J-V)$ and (b) luminance-voltage $(L-V)$ characteristics of OLED with $\mathrm{Cu}_{x} \mathrm{O}$ HIL deposited at different rates. Inset: schematic diagram of OLEDs. Reproduced from ref. 134 with permission from The Royal Society of Chemistry. their small band gap and low cost. ${ }^{\mathbf{1 3 2 4 8 - 2 5 5}}$ Under illumination, $\mathrm{Cu}_{x} \mathrm{O}$ produces electron/hole pairs that can generate hydroxyl radicals ( $\mathrm{HO}$ ) from water. This radical is capable of mineralizing most organic molecules. ${ }^{250}$ For water splitting applications, the majority charge carriers of the $\mathrm{Cu}_{x} \mathrm{O}$ (holes) oxidize water to oxygen gas $\left(\mathrm{O}_{2}\right)$, while the photo-generated minority charge carriers (electrons) reduce water to hydrogen gas $\left(\mathrm{H}_{2}\right){ }^{248,254,255}$ Significantly, the $\mathrm{Cu}_{x} \mathrm{O}$ conduction band is more negative than the redox potential of $\mathrm{H}^{+} / \mathrm{H}_{2}$, which allows sunlight to produce $\mathrm{H}_{2}$ from water. ${ }^{253}$

Unfortunately, the general photo-instability of $\mathrm{Cu}_{x} \mathrm{O}$ greatly hinders its direct application in photo-catalysis. ${ }^{248,256}$ To overcome this photo-instability effect, $\mathrm{Cu}_{x} \mathrm{O}$ is typically coupled with other semiconductors to form heterojunctions and it has been reported that $\mathrm{TiO}_{2}$ is one of the best candidates for this purpose. ${ }^{256,257}$ Additionally, nanostructuring of $\mathrm{Cu}_{x} \mathrm{O}$ can also significantly improve overall stability. ${ }^{256}$ Fortunately, the large surface area to volume ratio, which is provided by nanostructuring, significantly increases the effective surface area available for photo-catalytic reactions. ${ }^{249,250,252}$

It has also been reported that the photo-catalytic production rate of $\mathrm{H}_{2}$ can be significantly improved in the presence of alcohol, which provides suitable electron donors (also known as sacrificial agent/reagent). ${ }^{258-260}$ Barreca et al. have successfully demonstrated excellent performance of $\mathrm{Cu}_{2} \mathrm{O}$ photo-catalysis for generating $\mathrm{H}_{2}$ in the presence of methanol. ${ }^{13}$ They have suggested that methanol inhibits electron-hole recombination and acts partially as a hydrogen source. ${ }^{13}$ However, efficient photo-catalytic activity of $\mathrm{CuO}$ for $\mathrm{H}_{2}$ production has not been reported. This is despite the fact that the band gap of $\mathrm{CuO}$ is $1.2 \mathrm{eV}$, which makes $\mathrm{CuO}$ an efficient material to absorb sunlight. However, the position of the conduction band level limits its activity. Therefore, introducing a sacrificial agent is crucial to enable it to be used as a photo-catalyst. For example, Yao et al. have reported that $\mathrm{CuO}$ exhibits high photo-catalytic activity in oxalic acid solutions. ${ }^{253}$ Oxalic acid, which is a common pollutant in industrial wastewater, is a strong reductive agent and acts as an electron donor. ${ }^{261,262}$

\subsection{Antimicrobial applications}

The antimicrobial properties of $\mathrm{Cu}_{x} \mathrm{O}$, in particular $\mathrm{CuO}$, have attracted growing research interest. Nanostructured $\mathrm{Cu}_{x} \mathrm{O}$ commonly offers a strong degree of chemical and physical stability. Most bacterial cells have cellular membranes that contain pores in the nanometer range. $\mathrm{Cu}_{x} \mathrm{O}$, with dimensions less than $20 \mathrm{~nm}$, have shown antibacterial properties. ${ }^{11,263}$ The antimicrobial activity of $\mathrm{CuO}$ has been attributed to the production of reactive oxygen species (ROS) such as ${ }^{\circ} \mathrm{O}_{2}{ }^{-},{ }^{\cdot} \mathrm{HO}_{2}$, $\cdot \mathrm{OH}$ and $\mathrm{H}_{2} \mathrm{O}_{2}$ which can also occur without exposure to any visible light owing to the small band gap of $\mathrm{CuO}^{.64,265}$ The generated ROS interact with outer cell walls to generate free radicals. The radicals penetrate into the inner cell membranes which lead to the disruption of the internal contents of the cell. ${ }^{\mathbf{2 6 4 , 2 6 5}}$ The effectiveness of the antimicrobial agent appears to be related to the nature of the cell wall structures. ${ }^{\mathbf{2 6 3 , 2 6 5 - 2 6 7}}$ $S$. aureus is composed of multiple layers of peptidoglycan with 
numerous pores, which are suggested to be more susceptible to intracellular transductions. In contrast, the cell walls of $E$. coli are relatively thin, mainly consisting of peptidoglycan and outer layers of lipopolysaccharide, lipoprotein and phospholipids, which are less prone to being attacked by $\mathrm{CuO}$ nanoparticles. As a result, nanostructured $\mathrm{CuO}$ has a higher antimicrobial activity against $S$. aureus than $E$. coli. ${ }^{263,264}$

It has been demonstrated that nanostructured $\mathrm{CuO}$ antimicrobial activity can be enhanced by exposing it to light. ${ }^{11,264,268-270}$ As described in Section 4.2, light irradiation generates excited electron-hole pairs in the $\mathrm{CuO}$ and deactivation of the bacteria is possible via a photo-catalytic process. ${ }^{11,268}$ Akhavan et al. have reported an improvement of $22 \%$ of $\mathrm{CuO}$ antibacterial activity under illumination. ${ }^{\mathbf{1 1}}$
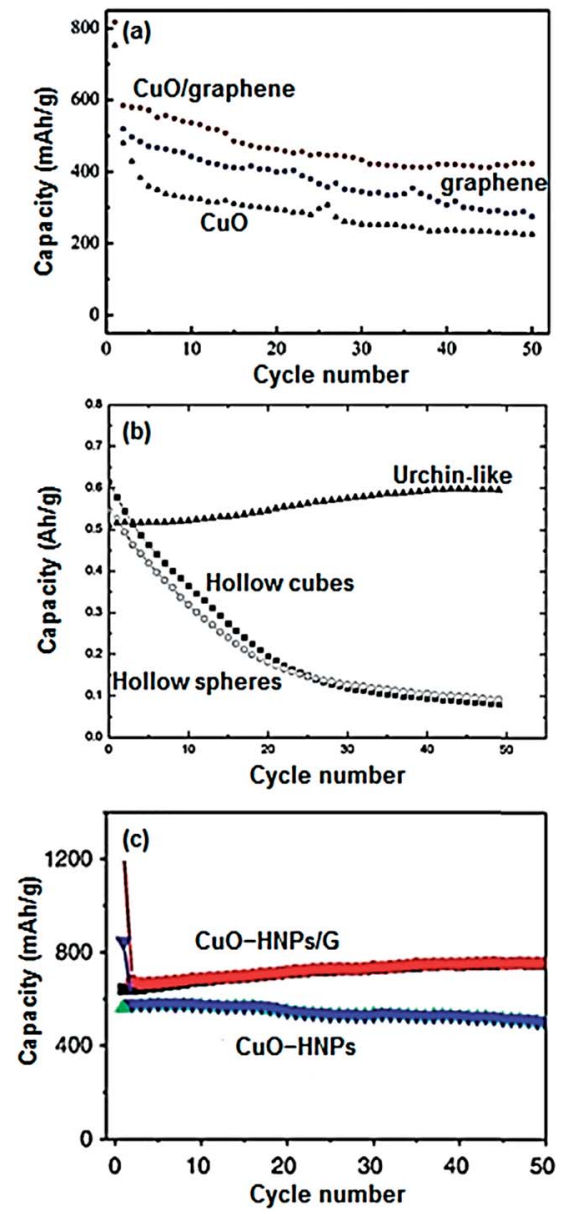

Fig. 12 Cycling profile of (a) bare $\mathrm{CuO}$, graphene and $\mathrm{CuO} /$ graphene electrode at a current density of $67 \mathrm{~mA} \mathrm{~g}^{-1}$, (b) CuO nanoparticles with three types of morphologies (urchin-like, hollow cubes and hollow spheres) at a current density of $150 \mathrm{~mA} \mathrm{~g}^{-1}$, (c) CuO hollow nanoparticles/graphene (CuO-HNPs/G) and $\mathrm{CuO}$ hollow nanoparticles (CuO-HNPs) at $50 \mathrm{~mA} \mathrm{~g}^{-1}$. (a) Reprinted fromY. J. Mai, X. L. Wang, J. Y. Xiang, Y. Q. Qiao, D. Zhang, C. D. Gu and J. P. Tu, Electrochim. Acta, 56, 2306-2311, copyright (2011) with permission from Elsevier, (b) reprinted with permission from (J. C. Park, J. Kim, H. Kwon and $\mathrm{H}$. Song, Adv. Mater., 2009, 21, 803) copyright (2009) by WILEY-VCH Verlag GmbH \& Co. KGaA, Weinheim, (c) reprinted from J. Zhou, L. Ma, H. Song, B. Wu and X. Chen, Electrochem. Commun., 13, 1357-1360, copyright (2011) with permission from Elsevier.

\subsection{Electrochemical applications}

The electrochemical properties of nanostructured $\mathrm{Cu}_{x} \mathrm{O}$ as electrodes for lithium ion batteries (LIB) have also been of growing research interest. $\mathrm{Cu}_{x} \mathrm{O}$ has many attractive advantages over conventional materials including high theoretical capacity (>600 and $>350 \mathrm{~mA} \mathrm{~h} \mathrm{~g}^{-1}$ for $\mathrm{CuO}$ and $\mathrm{Cu}_{2} \mathrm{O}$, respectively) and low cost. ${ }^{271-273}$ One of the major issues with the use of $\mathrm{Cu}_{x} \mathrm{O}$ in LIBs is its large volume variation during the $\mathrm{Li}^{+}$ion insertion/ extraction processes, which leads to severe mechanical strains and a rapid decay in capacity. ${ }^{271}$ Recently, there have been various reports demonstrating LIBs with high reversible capacity and cycling stability by synthesising $\mathrm{Cu}_{x} \mathrm{O}$ /graphene nanocomposites. ${ }^{271,274,275}$ Mai et al. reported an excellent reversible capacity of $583.5 \mathrm{~mA} \mathrm{~h}^{-1}$ with high cycling stability by incorporating $\mathrm{CuO}$ nanoparticles $(\sim 30 \mathrm{~nm})$ onto graphene sheets (Fig. 12a). The graphene sheets serve as a conductive network for fast electron transfer as well as buffered spaces to accommodate the $\mathrm{CuO}$ volume expansion/contraction during the $\mathrm{Li}^{+}$insertion/extraction process. ${ }^{274}$

Nanostructuring $\mathrm{Cu}_{x} \mathrm{O}$ into hollow nano/microstructures such as spheres, cubes or urchin-like structures increases its LIB performance. ${ }^{201,275-277}$ For example, Park et al. have successfully demonstrated that hollow $\mathrm{CuO}$ urchin-like nanoparticles possess a charge capacity above $560 \mathrm{~mA} \mathrm{~h} \mathrm{~g} \mathrm{~g}^{-1}$ (Fig. 12b). ${ }^{276}$ Wei et al. have discussed and listed three main advantages of hollow structures as anode materials for LIBs. ${ }^{277}$ Zhou et al. have reported excellent LIB performance by integrating hollow nanostructures of $\mathrm{CuO}$ with graphene. ${ }^{275}$ The composites exhibited a durable lifetime with reversible capacities as large as $640 \mathrm{~mA} \mathrm{~h} \mathrm{~g}^{-1}$ (Fig. 12c). ${ }^{275}$

\subsection{Electrochromic devices}

Nanostructured $\mathrm{Cu}_{2} \mathrm{O}$ electrochromic based systems, such as smart windows and optical displays, have been studied since the 1990s. ${ }^{130}$ It has been found that $\mathrm{Cu}_{2} \mathrm{O}$ exhibits cathodic electrochromism, being transparent under visible illumination in their oxidized state and almost black when switched to their reduced state in the presence of an electrolyte containing positive ions such as $\mathrm{H}^{+}, \mathrm{Li}^{+}$and $\mathrm{Na}^{+} .{ }^{\mathbf{1 3 0 , 2 7 8 - 2 8 1}}$ Generally, it has been found that the electrochromic process corresponds to the conversion of $\mathrm{Cu}_{2} \mathrm{O}$ (transparent) to $\mathrm{CuO}$ (black) in a reversible reduction-oxidation process (redox). ${ }^{278,281}$ To date, the best coloration efficiency obtained by $\mathrm{Cu}_{2} \mathrm{O}$ nanostructures has been up to $37 \mathrm{~cm}^{2} \mathrm{C}^{-1}$, which is only one-fourth of the best of those made from nanoporous $\mathrm{WO}_{3}\left(141.5 \mathrm{~cm}^{2} \mathrm{C}^{-1}\right) .{ }^{278,282}$ Unfortunately, nanostructured $\mathrm{Cu}_{2} \mathrm{O}$ requires high coloration voltage and shows poor stability, ${ }^{279}$ and further work should be carried out to solve such important issues.

\subsection{Sensing applications}

$\mathrm{Cu}_{x} \mathrm{O}$ offers great potential for the development of highly sensitive, yet low cost sensors. This includes optical, gas and bio sensors. Photodetectors are important devices that can be used in various applications, including thermal imaging systems, free-space communications, navigator aids and ozone-layer 
monitoring. ${ }^{283,284}$ Among the semiconductor materials, $\mathrm{Cu}_{x} \mathrm{O}$ has proven to be an attractive material for making photodetectors due to its relatively low band gap and remarkable optoelectronic properties..$^{\mathbf{7 0 2 8 4 - 2 8 7}}$

Sahoo et al. have demonstrated excellent performance of the photodetector based on $\mathrm{Cu}_{2} \mathrm{O}$ nanowires. ${ }^{\mathbf{2 8 5}}$ They adopted the metal-semiconductor-metal (MSM) technique for photon sensing under dark and illumination conditions. Fig. 13(a)-(d) illustrated SEM micrographs of four such MSM devices with channel lengths (i.e. spacing between the electrodes) of 210, 260, 580 and $720 \mathrm{~nm}$, respectively. ${ }^{285}$ They observed that the channel length significantly influenced the photocurrent and the bias dependence of the photo-to-darkcurrent ratio (Fig. 13(e)-(h)). ${ }^{285}$ Liao et al. reported the photoconductivity of $\mathrm{Cu}_{2} \mathrm{O}$ nanowires measured under dark and blue $(488 \mathrm{~nm})$ laser illumination and the conductance of nanowires increased from 0.7 to $4.3 \mu \mathrm{S}$ under illumination. Remarkably, the photoconductivity response time was less than three seconds with good reversibility and stability. ${ }^{70}$ $\mathrm{CuO}$ has also been extensively used in photodetector applications under visible and IR illumination (due to its relatively low band gap). ${ }^{\mathbf{2 8 4 , 2 8 6 - 2 8 8}}$ Recent comprehensive reviews on the usage of $\mathrm{CuO}$ in photodetection are found elsewhere. ${ }^{1}$

$\mathrm{Cu}_{x} \mathrm{O}$ also offers a great possibility for developing highly sensitive semiconductor-based gas sensors. The sensing properties of $\mathrm{Cu}_{x} \mathrm{O}$ can be improved by decreasing its size to nanoscale dimensions (comparable to twice of the Debye length) and by adding appropriate dopants. ${ }^{126,289}$ Catalytic nanoparticles such as $\mathrm{Pd},{ }^{290} \mathrm{Pt},{ }^{291} \mathrm{Ag}^{292}$ and $\mathrm{Au}^{291,293,294}$ attached to the $\mathrm{Cu}_{x} \mathrm{O}$ surface further increase its sensitivity, mainly due to spill-over effects. ${ }^{289} \mathrm{Cu}_{x} \mathrm{O}$ thin films have been demonstrated to be highly sensitive towards various gas species including $\mathrm{C}_{2} \mathrm{H}_{5} \mathrm{OH},{ }^{14,126,294-298} \mathrm{CO},{ }^{296,299,300} \mathrm{NO}_{2}$ (ref. 14 and 300) and $\mathrm{H}_{2} \mathrm{~S}^{53,290,301}$ (Fig. 14).

The ability to tune the shape and dimensions of $\mathrm{Cu}_{x} \mathrm{O}$ thereby creating superior chemical and physical properties can be exploited for chemosensors and biosensors. They also show unique surface chemistry, thermal and electrical properties and a high surface-to-volume ratio which enhance the sensitivity and response of electrochemical sensors. ${ }^{302}$

$\mathrm{Cu}_{x} \mathrm{O}$ has been used as a working electrode in electrochemical based biosensors including glucose sensors. ${ }^{303}$ Most electrochemical glucose sensors involve the use of the enzyme glucose oxidase. However, the greatest drawback of enzymatic sensors is their lack of stability due to the intrinsic nature of enzymes. ${ }^{\mathbf{3 0 4 , 3 0 5}}$ Development of non-enzymatic sensors, using $\mathrm{Cu}_{x} \mathrm{O}$ as the working electrode, has been reported..$^{305-307}$ Though non-enzymatic sensors are, by design, quite selective, CuO-based glucose sensors have fast response times, possess a high degree of repeatability and are extremely stable. ${ }^{303}$
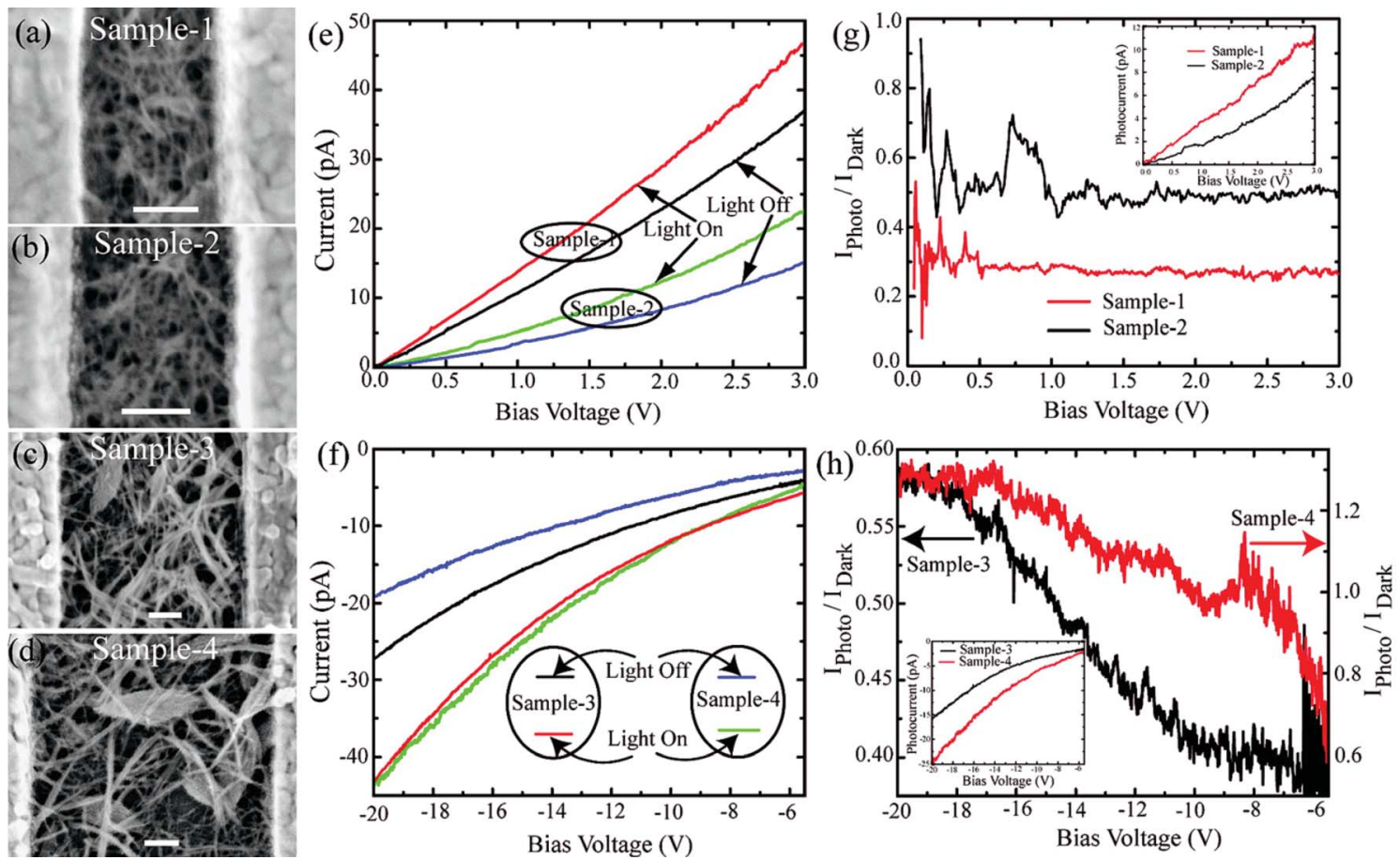

Fig. 13 (a-d) SEM micrographs of $\mathrm{Cu}_{2} \mathrm{O}$ nanowire based devices having electrode spacings of 210, 260, 580, and 720 nm, respectively. The electrodes are $3.2 \mu \mathrm{m}$ wide for all of the devices. The scale bars are $100 \mathrm{~nm}$. The current-voltage $(I-V)$ measurements are carried out at dark and under illumination conditions for all four samples. Depending on the interelectrode spacing, the samples are categorized into two sets, set I: sample-1 and sample-2; set II: sample-3 and sample-4. (e and f) I-V characteristics of set I and set II, respectively. (g and h) Plot of the ratio of photocurrent (I photo $)$ to the dark current $\left(I_{\text {dark }}\right)$ vs. bias voltage for set I and set II, respectively. Insets of $(\mathrm{g})$ and $(\mathrm{h})$ represent the photocurrent as a function of bias for set I and set II, respectively. Reprinted with permission from (S. Sahoo, S. Husale, B. Colwill, T.-M. Lu, S. Nayak and P. M. Ajayan, ACS Nano, 2009, 3, 3935-3944) copyright (2007) American Chemical Society. 
(a)

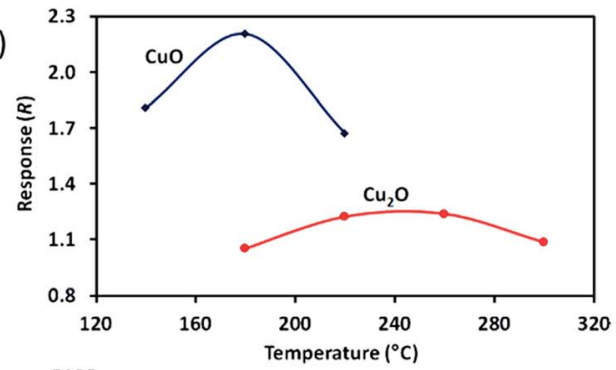

(b)

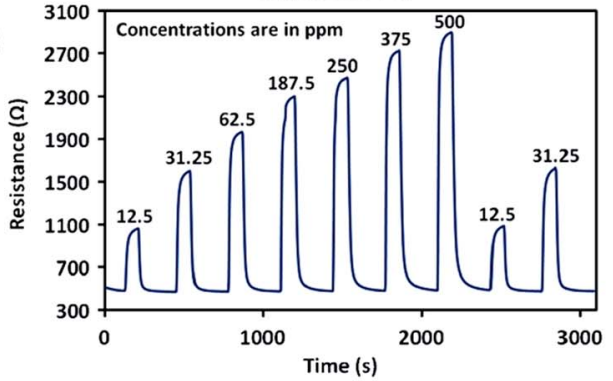

(c)

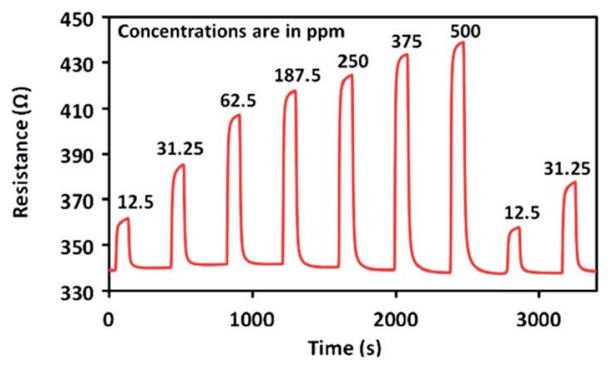

Fig. 14 (a) Sensor response curves of the $\mathrm{CuO}$ and $\mathrm{Cu}_{2} \mathrm{O}$ based sensors towards ethanol ( $12.5 \mathrm{ppm})$ at different operating temperatures, dynamic response of (b) $\mathrm{CuO}$ based sensors towards ethanol at the optimum operating temperature of $180{ }^{\circ} \mathrm{C}$ and (c) $\mathrm{Cu}_{2} \mathrm{O}$ based sensors towards ethanol at the optimum operating temperature of $260{ }^{\circ} \mathrm{C}$. Reprinted from, A. S. Zoolfakar, M. Z. Ahmad, R. A. Rani, J. Z. Ou, S. Balendhran, S. Zhuiykov, K. Latham, W. Wlodarski and K. Kalantar-zadeh, Sens. Actuator B Chem., 185, 620-627, copyright (2013) with permission Elsevier.

\subsection{Tribology and heat transfer applications}

A large number of studies have reported that adding metal oxides such as $\mathrm{Cu}_{x} \mathrm{O}$ in the form of nanoparticles to lubricants is an effective means to reduce wear and friction..$^{12,80,308-310}$ The friction-reduction and anti-wear behaviours are dependent on the characteristics of the nanoparticles including size (mostly in the range of 2-120 $\mathrm{nm}$ ), morphology and concentration. ${ }^{12}$ The colloidal effect, rolling friction effect, third body generation with nanomaterials and protective thin film formation mechanism have been proposed to justify the role of nanomaterials' anti-wear and friction-reduction properties. ${ }^{80}$

$\mathrm{Wu}$ et al. have compared the tribological properties of two lubricating oils (API-SF engine oil and Base oil) with $\mathrm{CuO}, \mathrm{TiO}_{2}$ and diamond nanoparticles used as additives. They found that $\mathrm{CuO}$ suspensions showed the highest reduction of the friction coefficient (due to viscosity and rolling effect) and the worn scar depth (owing to reduction of shearing stress) as compared to standard oils without nanoparticles. ${ }^{12}$ The shapes of nanoparticles such as spheres, rods, sheets and wires play crucial roles in tribology in monitoring the friction and anti-wear properties. Recently, Gausian et al. have revealed that lubricity enhancement is attributed to the synergistic effect of uninterrupted supplies of $\mathrm{CuO}$ nanorods under contact surfaces and their rolling mechanism. ${ }^{\mathbf{8 0}}$

In addition to the enhancement of tribological properties, nanofluids with dispersed $\mathrm{Cu}_{x} \mathrm{O}$ nanoparticles have great potential for improving heat transfer especially in improving the efficiency of chillers, refrigerators and air-conditioners. ${ }^{\mathbf{8 1 , 3 1 0 , 3 1 1}}$ Many studies have reported that mixtures with suspended $\mathrm{CuO}$ nanoparticles have higher thermal conductivity than the conventional host fluid. ${ }^{81}$ This is due to the thermal conductivity of $\mathrm{CuO}\left(76.5 \mathrm{~W} \mathrm{mK}^{-1}\right.$ which is much higher than ethylene glycol that has a value of $0.26 \mathrm{~W} \mathrm{mK}^{-1}$ ). Lee et al. have compared the thermal conductivity of $\mathrm{CuO}$ and $\mathrm{Al}_{2} \mathrm{O}_{3}$ nanoparticles suspended in ethylene glycol and found that the thermal conductivity of the $\mathrm{CuO}$ suspensions is $7 \%$ higher than the $\mathrm{Al}_{2} \mathrm{O}_{3}$ system. ${ }^{312}$

\subsection{Field emission applications}

The field emission (FE) properties of $\mathrm{Cu}_{x} \mathrm{O}$ are far less reported than other oxide materials such as $\mathrm{ZnO}, \mathrm{SnO}_{2}$ and $\mathrm{In}_{2} \mathrm{O}_{3}$. Due to its relatively narrow band gap, nanostructured $\mathrm{Cu}_{x} \mathrm{O}$ offers an attractive alternative to serve as a $\mathrm{FE}$ emitter. ${ }^{313-315}$ In a FE system the emitting capability is believed to be highly dependent on both the properties of the material and configuration of the cathode. ${ }^{34}$ It is known that materials with higher aspect ratios and sharp edges generally produce higher FE currents. ${ }^{55,313,315}$ Zhu et al. have reported FE measurements of $\mathrm{CuO}$ nanowire films with a low turn-on field of 3.5-4.5 $\mathrm{V} \mathrm{m}^{-1}$. They obtained a large current density of $0.45 \mathrm{~mA} \mathrm{~cm}^{-2}$ at an applied electric field of $7 \mathrm{~V} \mu \mathrm{m}^{-1} .^{314}$ Nanostructured $\mathrm{Cu}_{2} \mathrm{O}$ also exhibits relatively high $\mathrm{FE}$ performance. Shi et al. have demonstrated $\mathrm{Cu}_{2} \mathrm{O}$ micro-

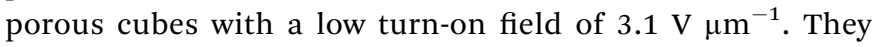
showed a high current density of $1 \mathrm{~mA} \mathrm{~cm}^{-2}$ at an applied electric field of $11 \mathrm{~V} \mathrm{\mu m}^{-1} \cdot{ }^{55}$ It has also been reported that $\mathrm{Cu}_{2} \mathrm{O}$ can be coupled with other metal oxides such as $\mathrm{ZnO}$ or $\mathrm{TiO}_{2}$ to enhance its FE performance (Fig. 15). ${ }^{315-317}$ This enhanced $\mathrm{FE}$ is attributed to the alteration in electron affinity of $\mathrm{Cu}_{x} \mathrm{O}$ by the other metal oxides forming a nano-heterojunction. ${ }^{317}$ Additionally, the presence of the heterojunctions promotes charge separation, where the electrons move to $\mathrm{ZnO}$ or $\mathrm{TiO}_{2}$ and the holes move to $\mathrm{Cu}_{2} \mathrm{O}$, which reduces the recombination of electron-hole pairs. ${ }^{317}$

\subsection{Other applications}

Nanostructured $\mathrm{Cu}_{x} \mathrm{O}$ has also been reported for many applications other than those presented in Sections 4.1 to 4.8. Of note, nanostructured $\mathrm{CuO}$ has been used in ceramic resistors ${ }^{\mathbf{3 1 8}}$ and supercapacitors. ${ }^{319,320}$ Nanostructured $\mathrm{Cu}_{2} \mathrm{O}$ has also been incorporated in memristors, ${ }^{321-323}$ heterogeneous catalysis, ${ }^{324-328}$ anti-fouling ${ }^{329-331}$ and thin-film transistors., ${ }^{2,332,333}$ Of course, there are other applications for which $\mathrm{Cu}_{x} \mathrm{O}$ has been used, but these are beyond the scope of this review paper. 

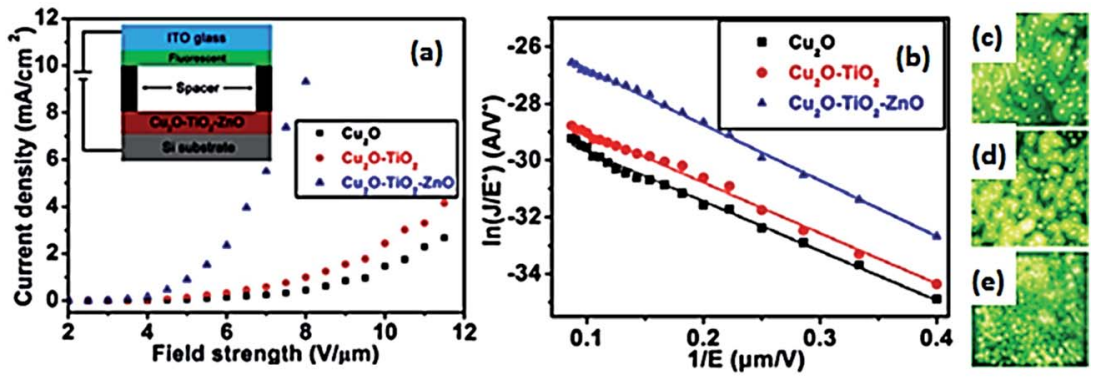

Fig. 15 (a) Field emission J-E curves, (b) corresponding $F-N$ plots of the samples. (c) - (e) Electron emission images of the pure $\mathrm{Cu}_{2} \mathrm{O}$ nanopines, $\mathrm{Cu}_{2} \mathrm{O}-\mathrm{TiO}_{2}-\mathrm{ZnO}$ composite samples, respectively. Reprinted with permission from (Y. Wang, K. Yu, H. H. Yin, C. Q. Song, Z. L. Zhang, S. C. Li, H. Shi, Q. F. Zhang, B. Zhao, Y. F. Zhang and Z. Q. Zhu, J. Phys. D Appl. Phys., 2013, 46), copyright (2013) by IOP Publishing Ltd.

\section{Conclusions and future outlook}

In this article, we have presented a comprehensive review of nanostructured $\mathrm{Cu}_{x} \mathrm{O}$ focusing on their properties, preparation, processing and device applications. An overview of the material properties, including crystal structures, electronic band structures, optical, vibrational, electrical, thermal and magnetic as well as superconductivity were presented. The effect of doping on the band gap and the enhancement in electrical properties was also detailed. Though much effort has been channeled in producing $\mathrm{n}$-type $\mathrm{Cu}_{x} \mathrm{O}$, the reproducibility and quality issues of the generated films are still questionable. This is potentially due to strong self-compensation effects and dopant solubility issues when n-type dopants are involved. Clearly, these issues must be overcome before high efficiency photovoltaic devices, based on homojunction $\mathrm{Cu}_{2} \mathrm{O}$ devices, will be realized.

Numerous synthesis techniques were reviewed, focusing on methods that produce nanostructured $\mathrm{Cu}_{x} \mathrm{O}$. Different synthesis techniques provide flexibility within the constraints of any particular application needs. Therefore, it is essential that exploration of nanostructure $\mathrm{Cu}_{x} \mathrm{O}$ synthesis continues and more innovative and low-cost routes are found in order to improve the future of the nanostructured $\mathrm{Cu}_{x} \mathrm{O}$ and its many applications.

Additionally, we have discussed the major applications of nanostructured $\mathrm{Cu}_{x} \mathrm{O}$ in optics, sensing, tribology, refrigeration, electrochemistry, photocatalysis, high- $T_{\mathrm{c}}$ superconductivity, electrochromics and antimicrobial devices. Due to the versatility of nanostructured $\mathrm{Cu}_{x} \mathrm{O}$, many more applications can be explored and are yet to be investigated.

To date, the majority of work in the area of $\mathrm{Cu}_{x} \mathrm{O}$ has been devoted to $\mathrm{CuO}$ and $\mathrm{Cu}_{2} \mathrm{O}$, whilst the number of reports on $\mathrm{Cu}_{4} \mathrm{O}_{3}$ are significantly lower. Despite the fact that there is a very limited number of reports available, the authors believe that the study of nanostructured $\mathrm{Cu}_{4} \mathrm{O}_{3}$ might provide possible new material insights and unique opportunities for incorporation into a wide-range of applications. Like other copper oxides, nanostructured $\mathrm{Cu}_{4} \mathrm{O}_{3}$ has the potential to be used in tribology and heat transfer applications as well as antimicrobial devices. As with the other copper oxide structures, the potential gains from developing a low-cost, nanostructured material, like $\mathrm{Cu}_{4} \mathrm{O}_{3}$ for any of these applications are extremely enticing and expected to be explored.

\section{Notes and references}

1 Q. Zhang, K. Zhang, D. Xu, G. Yang, H. Huang, F. Nie, C. Liu and S. Yang, Prog. Mater. Sci., 2014, 60, 208-337.

2 B. K. Meyer, A. Polity, D. Reppin, M. Becker, P. Hering, P. J. Klar, T. Sander, C. Reindl, J. Benz, M. Eickhoff, C. Heiliger, M. Heinemann, J. Blaesing, A. Krost, S. Shokovets, C. Mueller and C. Ronning, Phys. Status Solidi B, 2012, 249, 1487-1509.

3 K. P. Musselman, A. Marin, L. Schmidt-Mende and J. L. MacManus-Driscoll, Adv. Funct. Mater., 2012, 22, 2202-2208.

4 V. Gedzevičiūtè, N. Welter, U. Schüssler and C. Weiss, Archaeol. Anthropol. Sci., 2009, 1, 15-29.

5 P. Colomban, G. Sagon and X. Faurel, J. Raman Spectrosc., 2001, 32, 351-360.

6 P. E. Russell, J. Agric. Sci., 2005, 143, 11-25.

7 E. Somers, J. Sci. Food Agric., 1956, 7, 160-172.

8 I. Omae, Chem. Rev., 2003, 103, 3431-3448.

9 M. Srinivasan and G. Swain, Environ. Manage., 2007, 39, 423-441.

10 K. P. Musselman, A. Marin, A. Wisnet, C. Scheu, J. L. MacManus-Driscoll and L. Schmidt-Mende, Adv. Funct. Mater., 2011, 21, 573-582.

11 O. Akhavan and E. Ghaderi, Surf. Coat. Technol., 2010, 205, 219-223.

12 Y. Y. Wu, W. C. Tsui and T. C. Liu, Wear, 2007, 262, 819-825. 13 D. Barreca, P. Fornasiero, A. Gasparotto, V. Gombac, C. Maccato, T. Montini and E. Tondello, ChemSusChem, 2009, 2, 230-233.

14 D. D. Li, J. Hu, R. Q. Wu and J. G. Lu, Nanotechnology, 2010, 21, 485502.

15 T. Ito, H. Yamaguchi, K. Okabe and T. Masumi, J. Mater. Sci., 1998, 33, 3555-3566.

16 W. Y. Ching, Y. N. Xu and K. W. Wong, Phys. Rev. B: Condens. Matter Mater. Phys., 1989, 40, 7684-7695.

17 S. Sun and Z. Yang, RSC Adv., 2014, 4, 3804-3822.

18 S. Asbrink and L. J. Norrby, Acta Crystallogr., Sect. B: Struct. Crystallogr. Cryst. Chem., 1970, 26, 8-15.

19 M. Heinemann, B. Eifert and C. Heiliger, Phys. Rev. B: Condens. Matter Mater. Phys., 2013, 87, 115111.

20 J. F. Pierson, E. Duverger and O. Banakh, J. Solid State Chem., 2007, 180, 968-973. 
21 M. Okeeffe and J. O. Bovin, Am. Mineral., 1978, 63, 180-185. 22 C. Frondel, Am. Mineral., 1941, 26, 657-672.

23 A. E. Rakhshani and F. K. Barakat, Mater. Lett., 1987, 6, 3740.

24 M. T. S. Nair, L. Guerrero, O. L. Arenas and P. K. Nair, Appl. Surf. Sci., 1999, 150, 143-151.

25 M. F. Al-Kuhaili, Vacuum, 2008, 82, 623-629.

26 A. Chen, G. Yang, H. Long, F. Li, Y. Li and P. Lu, Thin Solid Films, 2009, 517, 4277-4280.

27 J. Ghijsen, L. H. Tjeng, J. Vanelp, H. Eskes, J. Westerink, G. A. Sawatzky and M. T. Czyzyk, Phys. Rev. B: Condens. Matter Mater. Phys., 1988, 38, 11322-11330.

28 A. A. Ogwu, E. Bouquerel, O. Ademosu, S. Moh, E. Crossan and F. Placido, J. Phys. D: Appl. Phys., 2005, 38, 266-271.

29 M. Izaki, Thin Solid Films, 2012, 520, 2434-2437.

30 K. Nakaoka, J. Ueyama and K. Ogura, J. Electrochem. Soc., 2004, 151, C661-C665.

31 J. C. Tauc, Optical Properties of Solids, North-Holland, Amsterdam, 1972.

32 J. F. Pierson, A. Thobor-Keck and A. Billard, Appl. Surf. Sci., 2003, 210, 359-367.

33 S. Rehman, A. Mumtaz and S. K. Hasanain, J. Nanopart. Res., 2011, 13, 2497-2507.

34 H. D. Zheng, J. Z. Ou, M. S. Strano, R. B. Kaner, A. Mitchell and K. Kalantar-Zadeh, Adv. Funct. Mater., 2011, 21, 21752196.

35 A. D. Yoffe, Adv. Phys., 1993, 42, 173-266.

36 M. Yang and J. He, J. Colloid Interface Sci., 2011, 355, 15-22.

37 J. Liu, X. Huang, Y. Li, K. M. Sulieman, X. He and F. Sun, J. Mater. Chem., 2006, 16, 4427-4434.

38 A. Shui, W. Zhu, L. Xu, D. Qin and Y. Wang, Ceram. Int., 2013, 39, 8715-8722.

39 Y. Gulen, F. Bayansal, B. Sahin, H. A. Cetinkara and H. S. Guder, Ceram. Int., 2013, 39, 6475-6480.

40 N. M. Basith, J. J. Vijaya, L. J. Kennedy, M. Bououdina and S. Hussain, J. Nanosci. Nanotechnol., 2014, 14, 2577-2583.

41 N. M. Basith, J. J. Vijaya, L. J. Kennedy and M. Bououdina, Mater. Sci. Semicond. Process., 2014, 17, 110-118.

42 Y. Peng, Z. Zhang, P. Thien Viet, Y. Zhao, P. Wu and J. Wang, J. Appl. Phys., 2012, 111.

43 L. Y. Isseroff and E. A. Carter, Chem. Mater., 2013, 25, 253265.

44 Y. Chang, J. J. Teo and H. C. Zeng, Langmuir, 2005, 21, 10741079.

45 B. Balamurugan and B. R. Mehta, Thin Solid Films, 2001, 396, 90-96.

46 P. Poulopoulos, S. Baskoutas, S. D. Pappas, C. S. Garoufalis, S. A. Droulias, A. Zamani and V. Kapaklis, J. Phys. Chem. C, 2011, 115, 14839-14843.

47 A. Thobor and J. F. Pierson, Mater. Lett., 2003, 57, 36763680.

48 J. F. Pierson, D. Wiederkehr and A. Billard, Thin Solid Films, 2005, 478, 196-205.

49 T. Ito, T. Kawashima, H. Yamaguchi, T. Masumi and S. Adachi, J. Phys. Soc. Jpn., 1998, 67, 2125-2131.

50 T. Ito, H. Yamaguchi, T. Masumi and S. Adachi, J. Phys. Soc. Jpn., 1998, 67, 3304-3309.
51 C. Malerba, F. Biccari, C. Leonor Azanza Ricardo, M. D'Incau, P. Scardi and A. Mittiga, Sol. Energy Mater. Sol. Cells, 2011, 95, 2848-2854.

52 K. Borgohain, N. Murase and S. Mahamuni, J. Appl. Phys., 2002, 92, 1292-1297.

53 J. T. Zhang, J. F. Liu, Q. Peng, X. Wang and Y. D. Li, Chem. Mater., 2006, 18, 867-871.

54 H.-H. Lin, C.-Y. Wang, H. C. Shih, J.-M. Chen and C.-T. Hsieh, J. Appl. Phys., 2004, 95, 5889-5895.

55 H. Shi, K. Yu, F. Sun and Z. Zhu, CrystEngComm, 2012, 14, 278-285.

56 H. Shi, K. Yu, Y. Wang, Q. Wang and Z. Zhu, Appl. Phys. A: Mater. Sci. Process., 2012, 108, 709-717.

57 M. M. Beg and S. M. Shapiro, Phys. Rev. B: Solid State, 1976, 13, 1728-1734.

58 M. Ivanda, D. Waasmaier, A. Endriss, J. Ihringer, A. Kirfel and W. Kiefer, J. Raman Spectrosc., 1997, 28, 487-493.

59 R. Mittal, S. L. Chaplot, S. K. Mishra and P. P. Bose, Phys. Rev. B: Condens. Matter Mater. Phys., 2007, 75, 174303.

60 W. Reichardt, F. Gompf, M. Ain and B. M. Wanklyn, Z. Phys. B: Condens. Matter, 1990, 81, 19-24.

61 L. Debbichi, M. C. M. de Lucas, J. F. Pierson and P. Kruger, J. Phys. Chem. C, 2012, 116, 10232-10237.

62 P. H. Shih, C. L. Cheng and S. Y. Wu, Nanoscale Res. Lett., 2013, 8, 398.

63 R. J. Elliott, Phys. Rev., 1961, 124, 340-345.

64 Y. K. Jeong and G. M. Choi, J. Phys. Chem. Solids, 1996, 57, 81-84.

65 A. P. Young and C. M. Schwartz, J. Phys. Chem. Solids, 1969, 30, 249-252.

66 S. Suda, S. Fujitsu, K. Koumoto and H. Yanagida, Jpn. J. Appl. Phys., Part 1, 1992, 31, 2488-2491.

67 D. Gopalakrishna, K. Vijayalakshmi and C. Ravidhas, Ceram. Int., 2013, 39, 7685-7691.

68 Y. Ohya, S. Ito, T. Ban and Y. Takahashi, in Key Engineering Materials, eds. N. Murata, K. Shinozaki and T. Kimura, 2000, pp. 113-116.

69 P. Shao, S. Deng, J. Chen, J. Chen and N. Xu, J. Appl. Phys., 2011, 109, 023710.

70 L. Liao, B. Yan, Y. F. Hao, G. Z. Xing, J. P. Liu, B. C. Zhao, Z. X. Shen, T. Wu, L. Wang, J. T. L. Thong, C. M. Li, W. Huang and T. Yu, Appl. Phys. Lett., 2009, 94, 113106.

71 Y. W. Tan, X. Y. Xue, Q. Peng, H. Zhao, T. H. Wang and Y. D. Li, Nano Lett., 2007, 7, 3723-3728.

72 S. Ishizuka and K. Akimoto, Appl. Phys. Lett., 2004, 85, 49204922.

73 K. Mizuno, M. Izaki, K. Murase, T. Shinagawa, M. Chigane, M. Inaba, A. Tasaka and Y. Awakura, J. Electrochem. Soc., 2005, 152, C179-C182.

74 P. Thien Viet, M. Rao, P. Andreasson, Y. Peng, J. Wang and K. B. Jinesh, Appl. Phys. Lett., 2013, 102, 032101.

75 D. O. Scanlon and G. W. Watson, J. Phys. Chem. Lett., 2010, 1, 2582-2585.

76 L. Q. Wang and J. Fan, Nanoscale Res. Lett., 2010, 5, 12411252.

77 X. Wei, H. Zhu, T. Kong and L. Wang, Int. J. Heat Mass Transfer, 2009, 52, 4371-4374. 
78 Y. J. Hwang, Y. C. Ahn, H. S. Shin, C. G. Lee, G. T. Kim, H. S. Park and J. K. Lee, Curr. Appl. Phys., 2006, 6, 10681071.

79 S. Walia, S. Balendhran, H. Nili, S. Zhuiykov, G. Rosengarten, Q. H. Wang, M. Bhaskaran, S. Sriram, M. S. Strano and K. Kalantar-zadeh, Prog. Mater. Sci., 2013, 58, 1443-1489.

80 R. Gusain and O. P. Khatri, J. Mater. Chem. A, 2013, 1, 56125619.

81 R. Saidur, S. N. Kazi, M. S. Hossain, M. M. Rahman and H. A. Mohammed, Renewable Sustainable Energy Rev., 2011, 15, 310-323.

82 H. Timm and J. Janek, Solid State Ionics, 2005, 176, 11311143.

83 X. Chen, D. Parker, M. H. Du and D. J. Singh, New J. Phys., 2013, 15, 043029.

84 H. A. Mintsa, G. Roy, C. T. Nguyen and D. Doucet, Int. J. Therm. Sci., 2009, 48, 363-371.

85 C. H. Li and G. P. Peterson, J. Appl. Phys., 2006, 99, 084314. 86 M. J. Nine, B. Munkhbayar, M. S. Rahman, H. Chung and H. Jeong, Mater. Chem. Phys., 2013, 141, 636-642.

87 H. Zhu, D. Han, Z. Meng, D. Wu and C. Zhang, Nanoscale Res. Lett., 2011, 6, 181.

88 P. A. Korzhavyi, I. L. Soroka, E. I. Isaev, C. Lilja and B. Johansson, Proc. Natl. Acad. Sci. U. S. A., 2012, 109, 686-689.

89 J. Leitner, D. Sedmidubský, B. Doušová, A. Strejc and M. Nevřiva, Thermochim. Acta, 2000, 348, 49-51.

90 M. W. Chase, C. A. Davies, J. R. Downey, D. J. Frurip, R. A. McDonald and A. N. Syverud, J. Phys. Chem. Ref. Data, 1985, 14, 1-926.

91 E. Gmelin, Indian J. Pure Appl. Phys., 1992, 30, 596-608.

92 L. V. Gregor, J. Phys. Chem., 1962, 66, 1645-1647.

93 J. H. Hu and H. L. Johnston, J. Am. Chem. Soc., 1951, 73, 4550-4551.

94 D. D. Lawrie, J. P. Franck and C.-T. Lin, Phys. C, 1998, 297, 59-63.

95 L. Pinsard-Gaudart, J. Rodriguez-Carvajal, A. Gukasov and P. Monod, Phys. Rev. B: Condens. Matter Mater. Phys., 2004, 69, 104408.

96 M. H. Whangbo and H. J. Koo, Inorg. Chem., 2002, 41, 35703577.

97 B. X. Yang, J. M. Tranquada and G. Shirane, Phys. Rev. B: Condens. Matter Mater. Phys., 1988, 38, 174-178.

98 B. X. Yang, J. M. Tranquada and G. Shirane, Phys. Rev. B: Condens. Matter Mater. Phys., 1988, 38, 174-178.

99 P. J. Brown, T. Chattopadhyay, J. B. Forsyth, V. Nunez and F. Tasset, J. Phys.: Condens. Matter, 1991, 3, 4281-4287.

100 M. S. Seehra and A. Punnoose, Solid State Commun., 2003, 128, 299-302.

101 X. G. Zheng, T. Mori, K. Nishiyama, W. Higemoto and C. N. Xu, Solid State Commun., 2004, 132, 493-496.

102 A. Punnoose, H. Magnone, M. S. Seehra and J. Bonevich, Phys. Rev. B: Condens. Matter Mater. Phys., 2001, 64, 174420.

103 D. Shang, K. Yu, Y. Zhang, J. Xu, J. Wu, Y. e. Xu, L. Li and Z. Zhu, Appl. Surf. Sci., 2009, 255, 4093-4096.
104 D. Gao, G. Yang, J. Li, J. Zhang, J. Zhang and D. Xue, J. Phys. Chem. C, 2010, 114, 18347-18351.

105 D. Gao, J. Zhang, J. Zhu, J. Qi, Z. Zhang, W. Sui, H. Shi and D. Xue, Nanoscale Res. Lett., 2010, 5, 769-772.

106 S. H. Pan, J. P. O'Neal, R. L. Badzey, C. Chamon, H. Ding, J. R. Engelbrecht, Z. Wang, H. Eisaki, S. Uchida, A. K. Guptak, K. W. Ng, E. W. Hudson, K. M. Lang and J. C. Davis, Nature, 2001, 413, 282-285.

107 M. A. Kastner, R. J. Birgeneau, G. Shirane and Y. Endoh, Rev. Mod. Phys., 1998, 70, 897-928.

108 J. M. Tranquada, H. Woo, T. G. Perring, H. Goka, G. D. Gu, G. Xu, M. Fujita and K. Yamada, Nature, 2004, 429, 534-538.

109 M. Karppinen and H. Yamauchi, Philos. Mag. B, 1999, 79, 343-366.

110 H. Yamauchi and M. Karppinen, Mater. Sci. Eng., B, 1998, 54, 92-97.

111 X. Han, K. Han and M. Tao, Electrochem. Solid-State Lett., 2009, 12, H89-H91.

112 K. Han and M. Tao, in Photovoltaics for the 21st Century 5, ed. M. Tao, P. Chang, K. Kakimoto, M. Sunkara, J. Brownson, C. Claeys, K. Rajeshwar and D. Yang, 2010, pp. 103-109.

113 X. Han, K. Han and M. Tao, Thin Solid Films, 2010, 518, 5363-5367.

114 C. A. N. Fernando and S. K. Wetthasinghe, Sol. Energy Mater. Sol. Cells, 2000, 63, 299-308.

115 Y. Okamoto, S. Ishizuka, S. Kato, T. Sakurai, N. Fujiwara, H. Kobayashi and K. Akimoto, Appl. Phys. Lett., 2003, 82, 1060-1062.

116 B. B. Li, L. Lin, H. L. Shen, F. E. Boafo, Z. F. Chen, B. Liu and R. Zhang, Eur. Phys. J.: Appl. Phys., 2012, 58, 20303.

117 K. Akimoto, S. Ishizuka, M. Yanagita, Y. Nawa, G. K. Paul and T. Sakurai, Sol. Energy, 2006, 80, 715-722.

118 S. Ishizuka, S. Kato, Y. Okamoto and K. Akimoto, Appl. Phys. Lett., 2002, 80, 950-952.

119 S. Ishizuka, S. Kato, Y. Okamoto and K. Akimoto, J. Cryst. Growth, 2002, 237-239(part 1), 616-620.

120 C. L. Chu, H. C. Lu, C. Y. Lo, C. Y. Lai and Y. H. Wang, Phys. B, 2009, 404, 4831-4834.

121 H.-C. Lu, C.-L. Chu, C.-Y. Lai and Y.-H. Wang, Thin Solid Films, 2009, 517, 4408-4412.

122 A. S. Reddy, H.-H. Park, V. S. Reddy, K. V. S. Reddy, N. S. Sarma, S. Kaleemulla, S. Uthanna and P. S. Reddy, Mater. Chem. Phys., 2008, 110, 397-401.

123 H. Zhu, J. Zhang, C. Li, F. Pan, T. Wang and B. Huang, Thin Solid Films, 2009, 517, 5700-5704.

124 A. R. Rastkar, A. R. Niknam and B. Shokri, Thin Solid Films, 2009, 517, 5464-5467.

125 N. G. Elfadill, M. R. Hashim, K. M. Chahrour, M. A. Qaeed and C. Wang, J. Mater. Sci.: Mater. Electron., 2014, 25, 262266.

126 A. S. Zoolfakar, M. Z. Ahmad, R. A. Rani, J. Z. Ou, S. Balendhran, S. Zhuiykov, K. Latham, W. Wlodarski and K. Kalantar-zadeh, Sens. Actuators, B, 2013, 185, 620-627.

127 K. J. Blobaum, D. Van Heerden, A. J. Wagner, D. H. Fairbrother and T. P. Weihs, J. Mater. Res., 2003, 18, 1535-1542. 
128 A. V. Richthofen, R. Domnick and R. Cremer, Fresenius' J. Anal. Chem., 1997, 358, 312-315.

129 P. K. Ooi, S. S. Ng, M. J. Abdullah, H. Abu Hassan and Z. Hassan, Mater. Chem. Phys., 2013, 140, 243-248.

130 N. Özer and F. Tepehan, Sol. Energy Mater. Sol. Cells, 1993, 30, 13-26.

131 K. Santra, C. K. Sarkar, M. K. Mukherjee and B. Ghosh, Thin Solid Films, 1992, 213, 226-229.

132 B. Balamurugan, B. R. Mehta, D. K. Avasthi, F. Singh, A. K. Arora, M. Rajalakshmi, G. Raghavan, A. K. Tyagi and S. M. Shivaprasad, J. Appl. Phys., 2002, 92, 3304-3310.

133 V. A. Gevorkyan, A. E. Reymers, M. N. Nersesyan and M. A. Arzakantsyan, J. Phys.: Conf. Ser., 2012, 350, 012027.

134 S. Kim, K. Hong, K. Kim, I. Lee and J.-L. Lee, J. Mater. Chem., 2012, 22, 2039-2044.

135 M. Vila, C. Diaz-Guerra and J. Piqueras, J. Phys. D: Appl. Phys., 2010, 43, 135403.

136 M. Kaur, K. P. Muthe, S. K. Despande, S. Choudhury, J. B. Singh, N. Verma, S. K. Gupta and J. V. Yakhmi, J. Cryst. Growth, 2006, 289, 670-675.

137 A. H. Jayatissa, K. Guo and A. C. Jayasuriya, Appl. Surf. Sci., 2009, 255, 9474-9479.

138 J. Liang, N. Kishi, T. Soga and T. Jimbo, Appl. Surf. Sci., 2010, 257, 62-66.

139 Y.-M. Juan, H.-T. Hsueh, T.-C. Cheng, C.-W. Wu and S.-J. Chang, ECS Solid State Lett., 2014, 3, P30-P32.

140 A. O. Musa, T. Akomolafe and M. J. Carter, Sol. Energy Mater. Sol. Cells, 1998, 51, 305-316.

141 G. Filipic and U. Cvelbar, Nanotechnology, 2012, 23, 194001. 142 Y. Yue, M. Chen, Y. Ju and L. Zhang, Scr. Mater., 2012, 66, 81-84.

143 L. D. Valladares, D. H. Salinas, A. B. Dominguez, D. A. Najarro, S. I. Khondaker, T. Mitrelias, C. H. W. Barnes, J. A. Aguiar and Y. Majima, Thin Solid Films, 2012, 520, 6368-6374.

144 X. Jiang, T. Herricks and Y. Xia, Nano Lett., 2002, 2, 13331338.

145 L. S. Huang, S. G. Yang, T. Li, B. X. Gu, Y. W. Du, Y. N. Lu and S. Z. Shi, J. Cryst. Growth, 2004, 260, 130-135.

146 F. Mumm and P. Sikorski, Nanotechnology, 2011, 22, 105605.

147 K. L. Zhang, C. Rossi, C. Tenailleau, P. Alphonse and J. Y. Chane-Ching, Nanotechnology, 2007, 18, 275607.

148 Q. Zhang, J. Wang, D. Xu, Z. Wang, X. Li and K. Zhang, J. Mater. Chem. A, 2014, 2, 3865-3874.

149 Q. B. Zhang, D. Xu, T. F. Hung and K. Zhang, Nanotechnology, 2013, 24, 065602.

150 R.-C. Wang and C.-H. Li, Cryst. Growth Des., 2009, 9, 22292234.

151 Q. Zhang, D. Xu, X. Zhou, X. Wu and K. Zhang, Small, 2014, 10, 935-943.

152 H. T. Hsueh, T. J. Hsueh, S. J. Chang, F. Y. Hung, T. Y. Tsai, W. Y. Weng, C. L. Hsu and B. T. Dai, Sens. Actuators, B, 2011, 156, 906-911.

153 Y. Fu, H. Lei, X. Wang, D. Yan, L. Cao, G. Yao, C. Shen, L. Peng, Y. Zhao, Y. Wang and W. Wu, Appl. Surf. Sci., 2013, 273, 19-23.
154 A. Chen, H. Long, X. Li, Y. Li, G. Yang and P. Lu, Vacuum, 2009, 83, 927-930.

155 M. Kawwam, F. Alharbi, A. Aldwayyan and K. Lebbou, Appl. Surf. Sci., 2012, 258, 9949-9953.

156 W. Seiler, E. Millon, J. Perrière, R. Benzerga and C. Boulmer-Leborgne, J. Cryst. Growth, 2009, 311, 33523358.

157 M. Kawwam, F. H. Alharbi, T. Kayed, A. Aldwayyan, A. Alyamani, N. Tabet and K. Lebbou, Appl. Surf. Sci., 2013, 276, 7-12.

158 K. P. Muthe, J. C. Vyas, S. N. Narang, D. K. Aswal, S. K. Gupta, D. Bhattacharya, R. Pinto, G. P. Kothiyal and S. C. Sabharwal, Thin Solid Films, 1998, 324, 37-43.

159 K. Kawaguchi, R. Kita, M. Nishiyama and T. Morishita, J. Cryst. Growth, 1994, 143, 221-226.

160 J. Li, Z. Mei, D. Ye, H. Liang, Y. Liu and X. Du, J. Cryst. Growth, 2012, 353, 63-67.

161 D. S. Darvish and H. A. Atwater, J. Cryst. Growth, 2011, 319, 39-43.

162 J. Medina-Valtierra, C. Frausto-Reyes, G. CamarilloMartinez and J. A. Ramirez-Ortiz, Appl. Catal., A, 2009, 356, 36-42.

163 J. Ramirez-Ortiza, T. Ogura, J. Medina-Valtierra, S. E. Acosta-Ortiz, P. Bosch, J. A. de los Reyes and V. H. Lara, Appl. Surf. Sci., 2001, 174, 177-184.

164 C. R. Crick and I. P. Parkin, J. Mater. Chem., 2011, 21, 14712-14716.

165 T. Kosugi and S. Kaneko, J. Am. Ceram. Soc., 1998, 81, 31173124.

166 J. Morales, L. Sanchez, F. Martin, J. R. Ramos-Barrado and M. Sanchez, Electrochim. Acta, 2004, 49, 4589-4597.

167 G. Q. Jian, L. Liu and M. R. Zachariah, Adv. Funct. Mater., 2013, 23, 1341-1346.

168 T. Ghodselahi, M. A. Vesaghi, A. Shafiekhani, A. Baghizadeh and M. Lameii, Appl. Surf. Sci., 2008, 255, 2730-2734.

169 D. Barreca, A. Gasparotto, C. Maccato, E. Tondello, O. I. Lebedev and G. Van Tendeloo, Cryst. Growth Des., 2009, 9, 2470-2480.

170 F. Pola-Albores, W. Antunez-Flores, P. Amezaga-Madrid, E. Rios-Valdovinos, M. Valenzuela-Zapata, F. ParaguayDelgado and M. Miki-Yoshida, J. Cryst. Growth, 2012, 351, 77-82.

171 P. Pattanasattayavong, S. Thomas, G. Adamopoulos, M. A. McLachlan and T. D. Anthopoulos, Appl. Phys. Lett., 2013, 102, 163505.

172 O. Waser, M. Hess, A. Guentner, P. Novak and S. E. Pratsinis, J. Power Sources, 2013, 241, 415422.

173 A. S. Zoolfakar, R. A. Rani, A. J. Morfa, S. Balendhran, A. P. O'Mullane, S. Zhuiykov and K. Kalantar-zadeh, J. Mater. Chem., 2012, 22, 21767-21775.

174 M. Izaki, M. Nagai, K. Maeda, F. B. Mohamad, K. Motomura, J. Sasano, T. Shinagawa and S. Watase, J. Electrochem. Soc., 2011, 158, D578-D584.

175 M. Izaki, T. Shinagawa, K.-T. Mizuno, Y. Ida, M. Inaba and A. Tasaka, J. Phys. D: Appl. Phys., 2007, 40, 3326-3329. 
176 J. Sasano, K. Motomura, M. Nagai, F. B. Mohamad and M. Izaki, Electrochemistry, 2011, 79, 831-837.

177 B. M. Fariza, J. Sasano, T. Shinagawa, S. Watase and M. Izaki, Thin Solid Films, 2012, 520, 2261-2264.

178 B. M. Fariza, J. Sasano, T. Shinagawa, H. Nakano, S. Watase and M. Izaki, J. Electrochem. Soc., 2011, 158, 621-625.

179 J. B. Cui and U. J. Gibson, J. Phys. Chem. B, 2010, 114, 64086412.

180 H. Wei, H. Gong, Y. Wang, X. Hu, L. Chen, H. Xu, P. Liu and B. Cao, CrystEngComm, 2011, 13, 6065-6070.

181 P. Poizot, C. J. Hung, M. P. Nikiforov, E. W. Bohannan and J. A. Switzer, Electrochem. Solid-State Lett., 2003, 6, C21-C25.

182 W. Y. Zhao, W. Y. Fu, H. B. Yang, C. J. Tian, M. H. Li, Y. X. Li, L. N. Zhang, Y. M. Sui, X. M. Zhou, H. Chen and G. T. Zou, CrystEngComm, 2011, 13, 2871-2877.

183 M. Xu, F. Wang, B. Ding, X. Song and J. Fang, RSC Adv., 2012, 2, 2240-2243.

184 G. Q. Yuan, H. F. Jiang, C. Lin and S. J. Liao, J. Cryst. Growth, 2007, 303, 400-406.

185 G. Yu, X. Hu, D. Liu, D. Sun, J. Li, H. Zhang, H. Liu and J. Wang, J. Electroanal. Chem., 2010, 638, 225230.

186 H. Ju, J. K. Lee, J. Lee and J. Lee, Curr. Appl. Phys., 2012, 12, 60-64.

187 S. Bijani, R. Schrebler, E. A. Dalchiele, M. Gabas, L. Martinez and J. R. Ramos-Barrado, J. Phys. Chem. C, 2011, 115, 21373-21382.

188 M. J. Siegfried and K.-S. Choi, J. Am. Chem. Soc., 2006, 128, 10356-10357.

189 M. J. Siegfried and K. S. Choi, Angew. Chem., Int. Ed., 2005, 44, 3218-3223.

190 S. Z. Li, H. Zhang, Y. J. Ji and D. R. Yang, Nanotechnology, 2004, 15, 1428-1432.

191 X. Wang, G. Xi, S. Xiong, Y. Liu, B. Xi, W. Yu and Y. Qian, Cryst. Growth Des., 2007, 7, 930-934.

192 M. H. Cao, C. W. Hu, Y. H. Wang, Y. H. Guo, C. X. Guo and E. B. Wang, Chem. Commun., 2003, 1884-1885.

193 C. Yang, X. Su, F. Xiao, J. Jian and J. Wang, Sens. Actuators, $B, 2011,158,299-303$.

194 Z. H. Yang, J. Xu, W. X. Zhang, A. P. Liu and S. P. Tang, J. Solid State Chem., 2007, 180, 1390-1396.

195 L. Liu, K. Hong, T. Hu and M. Xu, J. Alloys Compd., 2012, 511, 195-197.

196 H. Yu, J. Yu, S. Liu and S. Mann, Chem. Mater., 2007, 19, 4327-4334.

197 Z. Z. Chen, E. W. Shi, Y. Q. Zheng, W. J. Li, B. Xiao and J. Y. Zhuang, J. Cryst. Growth, 2003, 249, 294-300.

198 S. M. Gupta and M. Tripathi, Cent. Eur. J. Chem., 2012, 10, 279-294.

199 M. Rajamathi and R. Seshadri, Curr. Opin. Solid State Mater. Sci., 2002, 6, 337-345.

200 G.-D. Yao, Z.-B. Huo and F.-M. Jin, Res. Chem. Intermed., 2011, 37, 351-358.

201 L. Zhao, H. Chen, Y. Wang, H. Che, P. Gunawan, Z. Zhong, H. Li and F. Su, Chem. Mater., 2012, 24, 1136-1142.

202 A. Aslani and V. Oroojpour, Phys. B, 2011, 406, 144-149.

203 A. Aslani, Phys. B, 2011, 406, 150-154.
204 X.-Y. Yu, R.-X. Xu, C. Gao, T. Luo, Y. Jia, J.-H. Liu and X.-J. Huang, ACS Appl. Mater. Interfaces, 2012, 4, 1954-1962.

205 S. J. Chen, X. T. Chen, Z. L. Xue, L. H. Li and X. Z. You, J. Cryst. Growth, 2002, 246, 169-175.

206 J. W. Zhu, D. Li, H. Q. Chen, X. J. Yang, L. Lu and X. Wang, Mater. Lett., 2004, 58, 3324-3327.

207 R. Wu, Z. Ma, Z. Gu and Y. Yang, J. Alloys Compd., 2010, 504, 45-49.

208 C. H. Lu, L. M. Qi, J. H. Yang, D. Y. Zhang, N. Z. Wu and J. M. Ma, J. Phys. Chem. B, 2004, 108, 17825-17831.

209 W. Wang, L. Wang, H. Shi and Y. Liang, CrystEngComm, 2012, 14, 5914-5922.

210 K. Chen and D. Xue, J. Phys. Chem. C, 2013, 117, 2257622583.

211 Z. Yang, J. Xu, W. Zhang, A. Liu and S. Tang, J. Solid State Chem., 2007, 180, 1390-1396.

212 J. Huang, Y. Dai, C. Gu, Y. Sun and J. Liu, J. Alloys Compd., 2013, 575, 115-122.

213 H. Zhang, J. Feng and M. Zhang, Mater. Res. Bull., 2008, 43, 3221-3226.

214 C. Xia, X. Cai, W. Ning and G. Lin, Anal. Chim. Acta, 2011, 691, 43-47.

215 L. Zheng and X. Liu, Mater. Lett., 2007, 61, 2222-2226.

216 Y. Xu, D. Chen, M. Jiao and K. Xue, Mater. Res. Bull., 2007, 42, 1723-1731.

217 L. F. Gou and C. J. Murphy, Nano Lett., 2003, 3, 231-234.

218 M. Yin, C. K. Wu, Y. B. Lou, C. Burda, J. T. Koberstein, Y. M. Zhu and S. O'Brien, J. Am. Chem. Soc., 2005, 127, 9506-9511.

219 L. Gou and C. J. Murphy, J. Mater. Chem., 2004, 14, 735-738.

220 M. D. Susman, Y. Feldman, A. Vaskevich and I. Rubinstein, ACS Nano, 2014, 8, 162-174.

221 C.-H. Kuo and M. H. Huang, J. Phys. Chem. C, 2008, 112, 18355-18360.

222 J.-Y. Ho and M. H. Huang, J. Phys. Chem. C, 2009, 113, 14159-14164.

223 H. Xu, W. Wang and W. Zhu, J. Phys. Chem. B, 2006, 110, 13829-13834.

224 W. Z. Wang, G. H. Wang, X. S. Wang, Y. J. Zhan, Y. K. Liu and C. L. Zheng, Adv. Mater., 2002, 14, 67-69.

225 L. Armelao, D. Barreca, M. Bertapelle, G. Bottaro, C. Sada and E. Tondello, Thin Solid Films, 2003, 442, 48-52.

226 S. C. Ray, Sol. Energy Mater. Sol. Cells, 2001, 68, 307312.

227 C.-T. Hsieh, J.-M. Chen, H.-H. Lin and H.-C. Shih, Appl. Phys. Lett., 2003, 82, 3316-3318.

228 Y.-k. Su, C.-m. Shen, H.-t. Yang, H.-l. Li and H.-j. Gao, Trans. Nonferrous Met. Soc. China, 2007, 17, 783-786.

229 X. Hong, G. Wang, W. Zhu, X. Shen and Y. Wang, J. Phys. Chem. C, 2009, 113, 14172-14175.

$230 \mathrm{H} . \mathrm{Wu}, \mathrm{D}$. Lin and W. Pan, Appl. Phys. Lett., 2006, 89, 133125.

231 S. M. Sze and K. K. Ng, Physics of Semiconductor Devices, John Wiley and Sons, New Jersey, 2007.

232 R. P. Wijesundera, Semicond. Sci. Technol., 2010, 25, 045015.

233 Y. Hames and S. E. San, Sol. Energy, 2004, 77, 291-294. 
234 D. Li, C.-J. Chien, S. Deora, P.-C. Chang, E. Moulin and J. G. Lu, Chem. Phys. Lett., 2011, 501, 446-450.

235 A. R. Zainun, S. Tomoya, U. Mohd Noor, M. Rusop and I. Masaya, Mater. Lett., 2012, 66, 254-256.

236 M. Wang, L. Sun, Z. Lin, J. Cai, K. Xie and C. Lin, Energy Environ. Sci., 2013, 6, 1211-1220.

237 T. Minami, Y. Nishi and T. Miyata, Appl. Phys. Express, 2013, 6, 044101.

238 K. P. Musselman, A. Wisnet, D. C. Iza, H. C. Hesse, C. Scheu, J. L. MacManus-Driscoll and L. Schmidt-Mende, Adv. Mater., 2010, 22, E254-E285.

239 T. Minami, Y. Nishi, T. Miyata and J. Nomoto, Appl. Phys. Express, 2011, 4, 62301.

240 P. Raksa, S. Nilphai, A. Gardchareon and S. Choopun, Thin Solid Films, 2009, 517, 4741-4744.

241 M. H. Kim and Y. U. Kwon, J. Phys. Chem. C, 2011, 115, 23120-23125.

242 R. Sahay, J. Sundaramurthy, P. S. Kumar, V. Thavasi, S. G. Mhaisalkar and S. Ramakrishna, J. Solid State Chem., 2012, 186, 261-267.

243 S. Anandan, X. G. Wen and S. H. Yang, Mater. Chem. Phys., 2005, 93, 35-40.

244 H.-S. Koo, D.-T. Wang, Y.-K. Yu, S.-H. Ho, J.-Y. Jhang, M. Chen and M.-F. Tai, Jpn. J. Appl. Phys., 2012, 51, 10 NE18.

245 G. B. Murdoch, M. Greiner, M. G. Helander, Z. B. Wang and Z. H. Lu, Appl. Phys. Lett., 2008, 93, 083309.

246 W. P. Hu, K. Manabe, T. Furukawa and M. Matsumura, Appl. Phys. Lett., 2002, 80, 2640-2641.

247 T. Satoh and H. Fujikawa, Jpn. J. Appl. Phys., Part 1, 2007, 46, 1640-1642.

248 Z. Zheng, B. Huang, Z. Wang, M. Guo, X. Qin, X. Zhang, P. Wang and Y. Dai, J. Phys. Chem. C, 2009, 113, 1444814453.

249 M. Vaseem, A. Umar, Y. B. Hahn, D. H. Kim, K. S. Lee, J. S. Jang and J. S. Lee, Catal. Commun., 2008, 10, 11-16.

250 S. P. Meshram, P. V. Adhyapak, U. P. Mulik and D. P. Amalnerkar, Chem. Eng. J., 2012, 204-206, 158-168.

251 H. Xu, G. Zhu, D. Zheng, C. Xi, X. Xu and X. Shen, J. Colloid Interface Sci., 2012, 383, 75-81.

252 J. Liu, J. Jin, Z. Deng, S.-Z. Huang, Z.-Y. Hu, L. Wang, C. Wang, L.-H. Chen, Y. Li, G. Van Tendeloo and B.-L. Su, J. Colloid Interface Sci., 2012, 384, 1-9.

253 M.-h. Yao, Y.-g. Tang, L. Zhang, H.-h. Yang and J.-h. Yan, Trans. Nonferrous Met. Soc. China, 2010, 20, 1944-1949.

254 M. Hara, T. Kondo, M. Komoda, S. Ikeda, K. Shinohara, A. Tanaka, J. N. Kondo and K. Domen, Chem. Commun., 1998, 357-358.

255 P. E. de Jongh, D. Vanmaekelbergh and J. J. Kelly, Chem. Commun., 1999, 1069-1070.

256 G. K. Mor, O. K. Varghese, R. H. T. Wilke, S. Sharma, K. Shankar, T. J. Latempa, K. S. Choi and C. A. Grimes, Nano Lett., 2008, 8, 1906-1911.

257 W. Siripala, A. Ivanovskaya, T. F. Jaramillo, S. H. Baeck and E. W. McFarland, Sol. Energy Mater. Sol. Cells, 2003, 77, 229-237.

258 M. Ni, M. K. H. Leung, D. Y. C. Leung and K. Sumathy, Renewable Sustainable Energy Rev., 2007, 11, 401-425.
259 N. Strataki, V. Bekiari, D. I. Kondarides and P. Lianos, Appl. Catal., B, 2007, 77, 184-189.

260 J. Bandara, C. P. K. Udawatta and C. S. K. Rajapakse, Photochem. Photobiol. Sci., 2005, 4, 857-861.

261 S. Song, J. Tu, L. Xu, X. Xu, Z. He, J. Qiu, J. Ni and J. Chen, Chemosphere, 2008, 73, 1401-1406.

262 H. Yang, J. Yan, Z. Lu, X. Cheng and Y. Tang, J. Alloys Compd., 2009, 476, 715-719.

263 A. Azam, A. S. Ahmed, M. Oves, M. S. Khan and A. Memic, Int. J. Nanomed., 2012, 7, 3527-3535.

264 N. Ekthammathat, T. Thongtem and S. Thongtem, Appl. Surf. Sci., 2013, 277, 211-217.

265 M. S. Hassan, T. Amna, O. B. Yang, M. H. El-Newehy, S. S. Al-Deyab and M.-S. Khil, Colloids Surf., B, 2012, 97, 201-206.

266 I. Perelshtein, G. Applerot, N. Perkas, E. Wehrschuetz-Sigl, A. Hasmann, G. Guebitz and A. Gedanken, Surf. Coat. Technol., 2009, 204, 54-57.

267 G. Ren, D. Hu, E. W. C. Cheng, M. A. Vargas-Reus, P. Reip and R. P. Allaker, Int. J. Antimicrob. Agents, 2009, 33, 587-590.

268 M. Paschoalino, N. C. Guedes, W. Jardim, E. Mieluarski, J. A. Mielczarski, P. Bowen and J. Kiwi, J. Photochem. Photobiol., A, 2008, 199, 105-111.

269 O. Akhavan and E. Ghaderi, J. Mater. Chem., 2011, 21, 12935-12940.

270 P. Demchick and A. L. Koch, J. Bacteriol., 1996, 178, 768-773.

271 B. Wang, X.-L. Wu, C.-Y. Shu, Y.-G. Guo and C.-R. Wang, J. Mater. Chem., 2010, 20, 10661-10664.

272 J. Y. Xiang, J. P. Tu, L. Zhang, Y. Zhou, X. L. Wang and S. J. Shi, J. Power Sources, 2010, 195, 313-319.

273 L. Ji, Z. Lin, M. Alcoutlabi and X. Zhang, Energy Environ. Sci., 2011, 4, 2682-2699.

274 Y. J. Mai, X. L. Wang, J. Y. Xiang, Y. Q. Qiao, D. Zhang, C. D. Gu and J. P. Tu, Electrochim. Acta, 2011, 56, 23062311.

275 J. Zhou, L. Ma, H. Song, B. Wu and X. Chen, Electrochem. Commun., 2011, 13, 1357-1360.

276 J. C. Park, J. Kim, H. Kwon and H. Song, Adv. Mater., 2009, 21, 803-807.

277 W. Wei, Z. Wang, Z. Liu, Y. Liu, L. He, D. Chen, A. Umar, L. Guo and J. Li, J. Power Sources, 2013, 238, 376-387.

278 R. Neskovska, M. Ristova, J. Velevska and M. Ristov, Thin Solid Films, 2007, 515, 4717-4721.

279 M. Ristova, R. Neskovska and V. Mirčeski, Sol. Energy Mater. Sol. Cells, 2007, 91, 1361-1365.

280 T. J. Richardson, J. L. Slack and M. D. Rubin, Electrochim. Acta, 2001, 46, 2281-2284.

281 O. Akhavan, H. Tohidi and A. Z. Moshfegh, Thin Solid Films, 2009, 517, 6700-6706.

282 J. Z. Ou, S. Balendhran, M. R. Field, D. G. McCulloch, A. S. Zoolfakar, R. A. Rani, S. Zhuiykov, A. P. O'Mullane and K. Kalantar-zadeh, Nanoscale, 2012, 4, 5980-5988.

283 T. Y. Zhai, X. S. Fang, M. Y. Liao, X. J. Xu, H. B. Zeng, B. Yoshio and D. Golberg, Sensors, 2009, 9, 6504-6529.

284 S. B. Wang, C. H. Hsiao, S. J. Chang, K. T. Lam, K. H. Wen, S. C. Hung, S. J. Young and B. R. Huang, Sens. Actuators, A, 2011, 171, 207-211. 
285 S. Sahoo, S. Husale, B. Colwill, T.-M. Lu, S. Nayak and P. M. Ajayan, ACS Nano, 2009, 3, 3935-3944.

286 B. J. Hansen, N. Kouklin, G. Lu, I. K. Lin, J. Chen and X. Zhang, J. Phys. Chem. C, 2010, 114, 2440-2447.

287 S. Manna, K. Das and S. K. De, ACS Appl. Mater. Interfaces, 2010, 2, 1536-1542.

288 J. Xu, J.-L. Sun, J. Wei and J. Xu, Appl. Phys. Lett., 2012, 100, 251113.

289 A. Tricoli, M. Righettoni and A. Teleki, Angew. Chem., Int. Ed., 2010, 49, 7632-7659.

290 H. Kim, C. Jin, S. Park, S. Kim and C. Lee, Sens. Actuators, B, 2012, 161, 594-599.

291 X. Gou, G. Wang, J. Yang, J. Park and D. Wexler, J. Mater. Chem., 2008, 18, 965-969.

292 G. X. Zhu, H. Xu, Y. Y. Xiao, Y. J. Liu, A. H. Yuan and X. P. Shen, ACS Appl. Mater. Interfaces, 2012, 4, 744-751.

293 M. Ando, T. Kobayashi and M. Haruta, Catal. Today, 1997, 36, 135-141.

294 X.-W. Liu, F.-Y. Wang, F. Zhen and J.-R. Huang, RSC Adv., 2012, 2, 7647-7651.

295 H. T. Hsueh, S. J. Chang, F. Y. Hung, W. Y. Weng, C. L. Hsu, T. J. Hsueh, S. S. Lin and B. T. Dai, J. Electrochem. Soc., 2011, 158, J106-J109.

296 Y. Zhang, X. He, J. Li, H. Zhang and X. Gao, Sens. Actuators, $B, 2007,128,293-298$.

297 H. G. Zhang, Q. S. Zhu, Y. Zhang, Y. Wang, L. Zhao and B. Yu, Adv. Funct. Mater., 2007, 17, 2766-2771.

298 D. Barreca, E. Comini, A. Gasparotto, C. Maccato, C. Sada, G. Sberveglieri and E. Tondello, Sens. Actuators, B, 2009, 141, 270-275.

299 L. Liao, Z. Zhang, B. Yan, Z. Zheng, Q. L. Bao, T. Wu, C. M. Li, Z. X. Shen, J. X. Zhang, H. Gong, J. C. Li and T. Yu, Nanotechnology, 2009, 20, 085203.

300 Y.-S. Kim, I.-S. Hwang, S.-J. Kim, C.-Y. Lee and J.-H. Lee, Sens. Actuators, B, 2008, 135, 298-303.

301 F. Zhang, A. W. Zhu, Y. P. Luo, Y. Tian, J. H. Yang and Y. Qin, J. Phys. Chem. C, 2010, 114, 19214-19219.

302 T. Asefa, C. T. Duncan and K. K. Sharma, Analyst, 2009, 134, 1980-1990.

303 S. Park, H. Boo and T. D. Chung, Anal. Chim. Acta, 2006, 556, 46-57.

304 Z. J. Zhuang, X. D. Su, H. Y. Yuan, Q. Sun, D. Xiao and M. M. F. Choi, Analyst, 2008, 133, 126-132.

305 L. Zhang, H. Li, Y. H. Ni, J. Li, K. M. Liao and G. C. Zhao, Electrochem. Commun., 2009, 11, 812-815.

306 C. Batchelor-McAuley, Y. Du, G. G. Wildgoose and R. G. Compton, Sens. Actuators, B, 2008, 135, 230-235.

307 C. Batchelor-McAuley, G. G. Wildgoose, R. G. Compton, L. Shao and M. L. H. Green, Sens. Actuators, B, 2008, 132, 356-360.

308 A. H. Battez, R. Gonzalez, J. L. Viesca, J. E. Fernandez, J. M. D. Fernandez, A. Machado, R. Chou and J. Riba, Wear, 2008, 265, 422-428.
309 T. Oishi, M. Goto, A. Kasahara and M. Tosa, Surf. Interface Anal., 2004, 36, 1259-1261.

310 M. A. Kedzierski, Int. J. Refrig., 2012, 35, 1997-2002.

311 S.-s. Bi, L. Shi and L.-l. Zhang, Appl. Therm. Eng., 2008, 28, 1834-1843.

312 S. Lee, S. U. S. Choi, S. Li and J. A. Eastman, J. Heat Transfer, 1999, 121, 280-289.

313 C. T. Hsieh, J. M. Chen, H. H. Lin and H. C. Shih, Appl. Phys. Lett., 2003, 83, 3383-3385.

314 Y. W. Zhu, T. Yu, F. C. Cheong, X. J. Xui, C. T. Lim, V. B. C. Tan, J. T. L. Thong and C. H. Sow, Nanotechnology, 2005, 16, 88-92.

315 Y. Wang, S. C. Li, H. Shi and K. Yu, Nanoscale, 2012, 4, 7817-7824.

316 R. C. Wang and C. H. Li, Cryst. Growth Des., 2009, 9, 22292234.

317 Y. Wang, K. Yu, H. H. Yin, C. Q. Song, Z. L. Zhang, S. C. Li, H. Shi, Q. F. Zhang, B. Zhao, Y. F. Zhang and Z. Q. Zhu, J. Phys. D: Appl. Phys., 2013, 46, 175303.

318 S. Tanaka, Y. Sawai and A. Chiba, J. Eur. Ceram. Soc., 2004, 24, 289-293.

319 K. Krishnamoorthy and S.-J. Kim, Mater. Res. Bull., 2013, 48, 3136-3139.

320 D. P. Dubal, G. S. Gund, C. D. Lokhande and R. Holze, Mater. Res. Bull., 2013, 48, 923-928.

321 B. Singh, B. R. Mehta, D. Varandani, A. V. Savu and J. Brugger, Nanotechnology, 2012, 23, 495707.

322 A. Chen, S. Haddad, Y. C. Wu, Z. Lan, T. N. Fang and S. Kaza, Appl. Phys. Lett., 2007, 91, 123517.

323 W.-Y. Yang, W.-G. Kim and S.-W. Rhee, Thin Solid Films, 2008, 517, 967-971.

324 I. Najdovski, P. Selvakannan, S. K. Bhargava and A. P. O'Mullane, Nanoscale, 2012, 4, 6298-6306.

325 J. B. Reitz and E. I. Solomon, J. Am. Chem. Soc., 1998, 120, 11467-11478.

326 S. Song, R. Rao, H. Yang and A. Zhang, J. Phys. Chem. C, 2010, 114, 13998-14003.

327 Y. Xu, H. Wang, Y. Yu, L. Tian, W. Zhao and B. Zhang, J. Phys. Chem. C, 2011, 115, 15288-15296.

328 R. Prucek, L. Kvitek, A. Panacek, L. Vancurova, J. Soukupova, D. Jancik and R. Zboril, J. Mater. Chem., 2009, 19, 8463-8469.

329 S. Zhuiykov, E. Kats, D. Marney and K. Kalantar-zadeh, Prog. Org. Coat., 2011, 70, 67-73.

330 S. Zhuiykov and K. Kalantar-zadeh, Electrochim. Acta, 2012, 73, 105-111.

331 S. Zhuiykov, D. Marney, E. Kats and K. Kalantar-Zadeh, Sens. Actuators, B, 2011, 153, 312-320.

332 E. Fortunato, V. Figueiredo, P. Barquinha, E. Elamurugu, R. Barros, G. Goncalves, S.-H. K. Park, C.-S. Hwang and R. Martins, Appl. Phys. Lett., 2010, 96, 192102.

333 X. Zou, G. Fang, L. Yuan, M. Li, W. Guan and X. Zhao, IEEE Electron Device Lett., 2010, 31, 827-829. 